\title{
Influence of Cold-Wire Submerged Arc Welding on the Toughness of Microalloyed Steel
}

\author{
A detailed analysis of fracture toughness indicated that \\ the addition of an electrically cold wire to the TSAW process \\ improved the toughness in the HAZ of welded X7O microalloyed steel
}

BY M. MOHAMMADIJOO, L. COLLINS, R. LAZOR, H. HENEIN, AND D. G. IVEY

\begin{abstract}
The structural performance of microalloyed steel weld joints is essentially dependent on the microstructural characteristics of the heat-affected zone (HAZ). However, the microstructure is adversely impacted by the heat input of the welding process. As such, an X70 microalloyed steel was welded via a recently developed welding process, i.e., tandem submerged arc welding (TSAW) with an additional cold wire (cold-wire TSAW), and compared with the conventional TSAW process in terms of the HAZ microstructure and toughness. The heat introduced to the weldment was essentially reduced by the addition of a cold wire in the welding process, which changed the properties in the HAZ. The results of fracture toughness testing using single-edge notched tension (SENT) testing, a recently developed test method, and Charpy V-notch (CVN) impact testing showed an improvement in the toughness of the HAZ of the cold-wire TSAW weld. This improvement was attributed to the formation of a lower fraction of M-A constituents and smaller ferrite/bainite grains with higher boundary misorientation angle, due to the reduced heat input by cold wire addition. Furthermore, the microstructural analysis indicated the morphology and interspacing of the M-A constituents within the coarsegrained heat-affected zone (CGHAZ) played a significant role on the toughness of the HAZ.
\end{abstract}

\section{KEYWORDS}

- Microalloyed Steel • Cold-Wire TSAW

- Fracture Toughness • M-A Constituents • CGHAZ

\section{Introduction}

In developing microalloyed steel structures, such as pipelines, pressure vessels, and automotives, the steel is subjected to welding/joining, which results in the formation of a relatively narrow region adjacent to the fusion zone known as the coarse-grained heat-affected zone (CGHAZ). The CGHAZ is generally believed to exhibit the poorest fracture toughness relative to the rest of the steel structure (Ref. 1). Several methods have been commonly used to assess the fracture toughness in the CGHAZ (Refs. 2-5); however, during the past decade, several endeavors have been devoted to developing a fracture toughness test method, which is less conservative relative to the conventional methods according to engineering critical assessment (ECA) (Refs. 4, 5-8).

An ECA, also known as a fracture toughness analysis, is a fitness-for-service procedure that uses fracture mechanics principles to determine the defect tolerance of critical safety items, such as pipelines and pressure vessels. An ECA is used to decide whether a given flaw is safe from brittle fracture, plastic collapse, creep, and fatigue crack growth under certain loading conditions. According to the loading conditions that steel pipelines are exposed to, the single-edge notched tension (SENT) test method has been developed to investigate the toughness of the steel pipelines (Refs. 6-10). The fracture toughness in the heat-affected zone (HAZ) is controlled by several microstructural factors, such as grain size, types of phases, and morphology of secondary phases, which are directly influenced by the heat input of the welding process (Refs. 11-13).

During the past several decades, the relationship between microstructure and mechanical properties of high-strength microalloyed steels has been extensively studied in an effort to improve the fracture toughness and strength of this type of steel without substantially increasing the costs of steel production and structure manufacturing, i.e., welding/joining. However, although an excellent combination of strength and toughness can be achieved by thermomechanical-controlled processing (TMCP) and alloying design, the fracture toughness deteriorates in the HAZ, particularly the CGHAZ, due to the high welding heat input. This properties deterioration is caused by the microstructural changes, i.e., the formation of large prior austenite grains (PAGs) and the martensite-austenite (M-A) constituents in the CGHAZ (Refs. 14-16), as a result of the thermal cycle and peak temperatures (above $\sim 1300^{\circ} \mathrm{C}$ ) that the steel experiences during welding. 


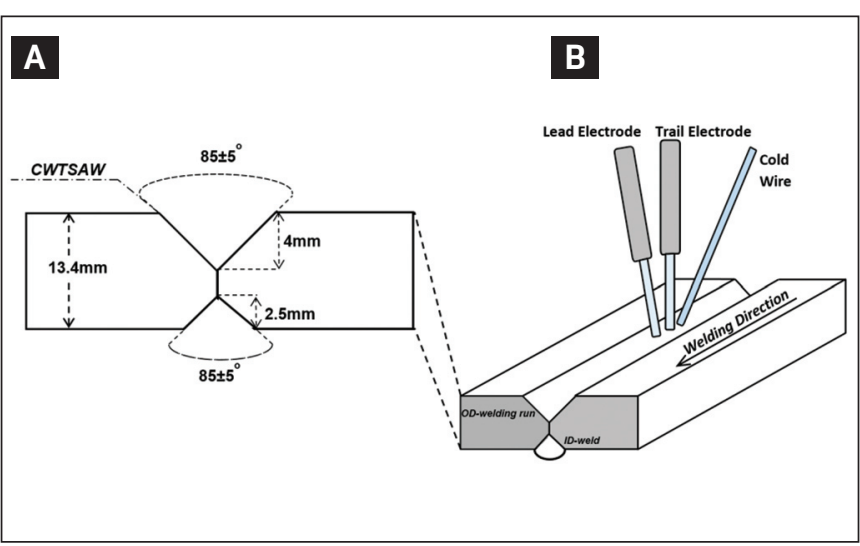

Fig. 1-A - X70 steel joint geometry indicating both ID and OD bevels; $B$ - schematic view of cold-wire TSAW process with positioning of the electrodes and cold wire.

The studies done by Moeinifar et al. (Refs. 17, 18) showed that fraction and morphology of M-A particles, as well as the PAG size, influence the Charpy impact toughness in the CGHAZ. Gharibshahiyan et al. (Ref. 19) have reported that the coarser PAGs formed in the CGHAZ adversely affect the toughness of the HAZ. Davis et al. (Refs. 20,21) and Reichert et al. (Ref. 22) found that cleavage crack initiation and transgranular fracture take place in the HAZ due to the formation of a network of enlarged M-A constituents along and within the PAGs in the CGHAZ. Li et al. (Ref. 23) showed that the formation of a lower fraction of small M-A islands did not cause a detrimental effect on the HAZ toughness. However, the fraction and size of M-A constituents were essentially dependent on the PAG size. The work done by Yu et al. (Ref. 24) concluded that more M-A constituents with a larger size were formed by coarsening the PAG in the CGHAZ.

It was also found that a microstructure comprised of a mixture of the coarse PAGs and coarse M-A constituents resulted in the promotion of brittle fracture in the CGHAZ. The temperature and kinetics of phase transformations taking place during cooling are influenced by the PAG size (Refs. 25, 26). The martensite start temperature (Ms) increases with an increase in the PAG size, which results in a higher volume fraction of martensite (Refs. 27, 28). However, the PAG size and the fraction of the M-A constituents are greatly influenced by the welding heat input. Shome (Ref. 29) and Zhang et al. (Ref. 30) studied the dependency of the PAG size on the local thermal cycle in the HAZ. They reported the PAG size increased by increasing the welding heat input. Refining the PAG size in the HAZ influenced the transformation products, particularly the $\mathrm{M}$-A constituents, and consequently the toughness (Refs. 23, 31, 32). However, there has only been limited work devoted to the correlation of the PAG size and M-A constituents in the HAZ with the welding heat input (Refs. 31-34).

With the above in mind, due to the adverse effect of high welding heat input on the properties of the HAZ, this study evaluates the microstructure and the fracture toughness of the HAZ when the welding heat input is reduced through the addition of a cold wire in the tandem submerged arc welding (coldwire TSAW) process. It is possible to reduce the heat input by reducing the current and voltage of the electrodes. However, this type of reduction can result in substantial adverse effects

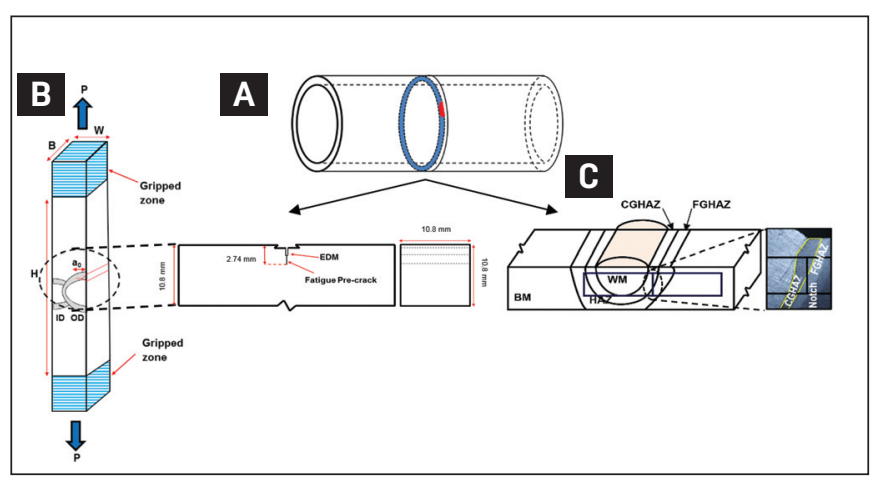

Fig. 2 - A - Schematic of a circumferential flaw formed through the wall thickness of a typical pipe; B - SENT specimen geometry with a notch placed in the HAZ for 13.4-mmthick pipe; and $\mathrm{C}-$ extraction of subsize CVN specimen from the weld sample.

on the penetration depth and macrostructure of the weld and, consequently, the properties of the weld. The penetration depth and width of the weld decrease as the welding current and voltage are reduced, which result in the formation of defects (due to the incomplete fusion) through the weld and the formation of crack initiation sites. Accordingly, the weld specimens were fabricated in a two-pass welding condition (i.e., one inner-diameter [ID] and one outer-diameter [OD] welding run) using the recently developed cold-wire TSAW process (Ref. 35) and compared with the conventional TSAW process. The developed process improves the throughput of the welding process by addition of an electrode, which is electrically cold, i.e., no current and voltage, while retaining appropriate weld appearance characteristics.

In the TSAW process, the welding deposition rate is increased by increasing the current and voltage of the electrodes (i.e., heat input), which affects the properties in the HAZ. However, in cold-wire TSAW, the additional cold wire fed into the weld pool increases the deposition rate with no increase in the welding heat input (Refs. 35-37). In addition, the heat input is moderated by the cold wire due to consumption of some of the excess energy of the trail electrode, which lowers the amount of the heat introduced to the weldment. As such, a weld with smaller dilution and a narrower HAZ is achieved due to the lower welding heat input (Refs. 35, 38). Moreover, since heat input directly influences the HAZ microstructure and properties, lowering the welding heat input results in a refinement of the microstructure with a corresponding effect on the properties, which are discussed in detail in this paper. Microstructural alterations in the CGHAZ are characterized using tint-etching optical microscopy (TEOM), scanning electron microscopy (SEM), and electron backscattered diffraction (EBSD). The Charpy V-notch (CVN) testing and SENT testing were conducted to evaluate the toughness changes in the HAZ by cold wire addition.

\section{Experimental Procedure}

\section{Materials and Welding Procedure}

Cold-wire TSAW and the conventional TSAW processes were conducted on beveled X70 microalloyed steel plates 

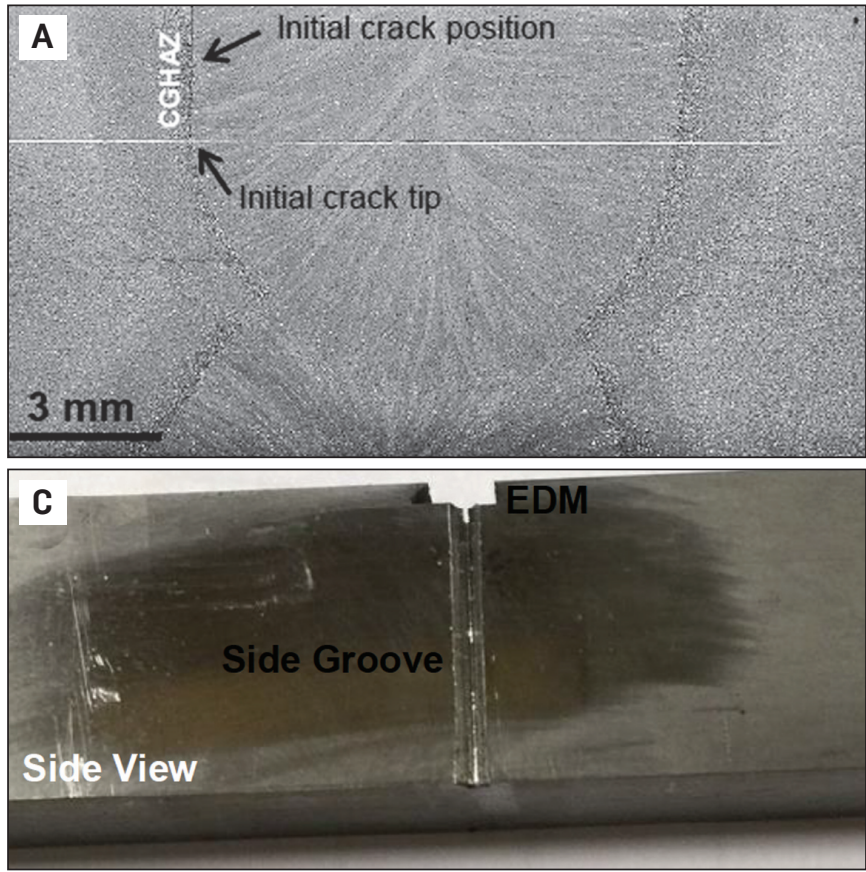
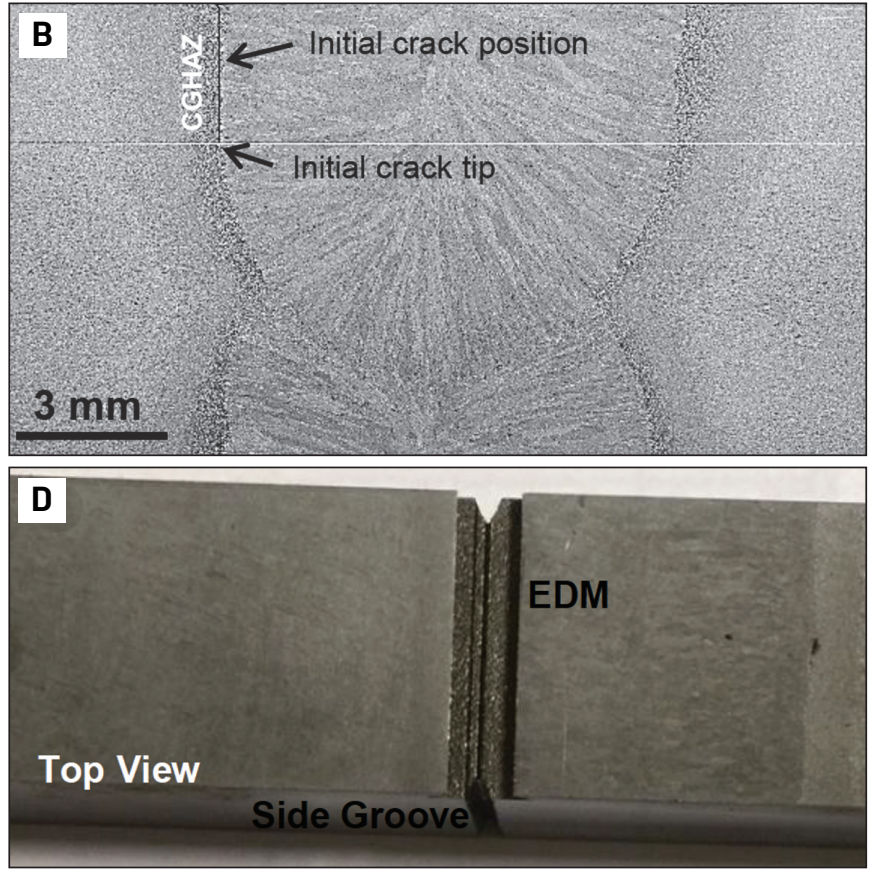

Fig. 3 - Macrographs of the following: A - Cold-wire TSAW and B - TSAW samples indicating the position of the initial crack for SENT testing with the initial crack tip positioned in the CGHAZ; $C$ and D - side and top views, respectively, of a SENT specimen for the cold-wire TSAW sample.

with a thickness of $13.4 \pm 0.3 \mathrm{~mm}$, manufactured through thermomechanical-controlled processing (TMCP) (Ref. 39). A typical X70 microalloyed steel has a yield strength $\left(\sigma_{\mathrm{ys}}\right)$ and ultimate tensile strength $\left(\sigma_{\text {uts }}\right)$ of 480 and $610 \mathrm{MPa}$, respectively, with a CVN impact energy as high as $150 \mathrm{~J}$. Two 4-mm-diameter BA-S2Mo electrodes, and one cold wire with the same diameter and composition as the electrodes, were chosen according to AWS A5.23 for arc generation and filling of the bevel. The BA-S2Mo electrodes are mainly used for welding of X70 microalloyed steels to provide a slightly higher carbon content in the weld pool. The higher carbon content in the weld retards the transformation of austenite to ferrite in the weld until the austenite-to-ferrite transformation starts in the CGHAZ. The delay in the austenite-toferrite transformation in the weld due to the slightly higher carbon content results in the formation of low-temperaturetransformation products, particularly acicular ferrite in the weld, which lead to higher fracture toughness of the weld. The BA-S2Mo electrode with the specified composition is also widely used by many pipe manufacturers. The granular flux BF 6.4 was selected according to EN 760 (Bavaria, Germany) with a basicity index of 1.7 , and is typically used for welding X70 and X80 microalloyed steels.

Table 1 indicates the chemical compositions of the microalloyed steel and consumable electrodes. Pcm, the weld- ing crack susceptibility index for low-carbon microalloyed steels given in Table 1, was calculated according to the ItoBessyo equation (Ref. 40).

Two $85 \pm 5$ deg V-shaped bevels, $4.0 \pm 0.2 \mathrm{~mm}$ and $2.5 \pm$ $0.2 \mathrm{~mm}$ in depth, were machined in the steel plates prior to welding - Fig. 1A. One ID and one OD weld run were conducted for each welding process to ensure complete joint penetration and complete filling of the root opening between the two pieces of steel - Fig. 1B. Any opening between the steel sheets would act as a crack during fracture toughness testing.

In this study, the aim was to specifically evaluate the influence of cold wire addition to the OD welding pass on welding heat input and, consequently, the microstructure and toughness of the HAZ. Accordingly, the welding parameters for the ID weld run (performed via TSAW) were similar for all the weld samples; only the OD welding parameters varied (Table 2). Direct current electrode positive (DCEP) and square wave alternating current (ACSQ) polarity were employed, using constant current type power sources to operate the lead and trail electrodes in the OD weld run, respectively. Both the lead and trail electrodes in the ID weld run were operated in ACSQ polarity. As stated earlier, the additional wire is electrically cold with no current and voltage. The OD welding parameters and the welding process

Table 1- Nominal Chemical Composition of X70 Microalloyed Steel and the Electrodes (wt-\%)

\begin{tabular}{|c|c|c|c|c|c|c|c|c|c|}
\hline X70 Steel & $\begin{array}{c}C \\
0.046\end{array}$ & $\begin{array}{c}\mathrm{N} \\
0.0098\end{array}$ & $\begin{array}{c}\mathrm{V}+\mathrm{Mo}+\mathrm{Nb}+\mathrm{Ti} \\
0.21\end{array}$ & $\begin{array}{c}P \\
0.01\end{array}$ & $\begin{array}{c}S \\
0.001\end{array}$ & $\begin{array}{l}\mathrm{Mn} \\
1.76\end{array}$ & $\begin{array}{c}\mathrm{Si} \\
0.24\end{array}$ & $\begin{array}{c}\mathrm{Cu}+\mathrm{Ni}+\mathrm{Cr} \\
0.54\end{array}$ & $\begin{array}{l}\text { Pcm } \\
0.175\end{array}$ \\
\hline $\begin{array}{l}\text { Electrode + } \\
\text { Cold Wire }\end{array}$ & $\begin{array}{c}C \\
0.10\end{array}$ & $\begin{array}{c}P \\
0.007\end{array}$ & $\begin{array}{c}S \\
0.01\end{array}$ & $\begin{array}{l}\text { Mn } \\
1.04\end{array}$ & $\begin{array}{l}\mathrm{Si} \\
0.1\end{array}$ & $\begin{array}{l}\text { Mo } \\
0.56\end{array}$ & $\begin{array}{c}\mathrm{Ni} \\
0.02\end{array}$ & $\begin{array}{c}\mathrm{Cr} \\
0.03\end{array}$ & $\begin{array}{c}\mathrm{Cu} \\
0.03\end{array}$ \\
\hline
\end{tabular}


Table 2 - ID and OD Welding Process Parameters

\begin{tabular}{cccc} 
Process Parameters & $\begin{array}{c}\text { ID-Weld } \\
\text { (Polarity) }\end{array}$ & $\begin{array}{c}\text { OD-Weld } \\
\text { Cold-Wire TSAW } \\
\text { (Polarity) }\end{array}$ & $\begin{array}{c}\text { OD-Weld } \\
\text { TSAW } \\
\text { (Polarity) }\end{array}$ \\
\hline Current - Lead Electrode (A) & & 1040 (DCEP) & 1040 (DCEP) \\
Current - Trail Electrode (A) & 880 (ACSQ) & 830 (ACSQ) & 830 (ACSQ) \\
Voltage - Lead Electrode (V) & 770 (ACSQ) & 30 & 30 \\
Voltage - Trail Electrode (V) & 28 & 160 & 34 \\
Welding Travel Speed (cm/min) & 30 & Lagging & 160 \\
Cold Wire Position & 160 & 63 deg & NA \\
Cold Wire Angle & NA & 25.4 & NA \\
Cold Wire Feed Speed (cm/min) & NA & & NA \\
\end{tabular}

setup were developed based on the optimized welding parameters, which are discussed elsewhere (Refs. 35,38 ). The fabricated welds were visually inspected prior to further investigation to ensure that no macro-level defects, such as undercutting, melt-through, surface porosity, and hot cracking, were formed in the weld region and the HAZ. The nominal heat input for both welding processes was constant and set at $22.2 \mathrm{~kJ} / \mathrm{cm}$; however, as stated earlier, cold wire addition results in a reduction in the welding heat input. All welding parameters were the same for both processes other than the additional cold wire.

\section{Fracture Toughness Testing}

From the eight welding runs conducted by the TSAW and cold-wire TSAW processes, eight weld coupons were cut in the transverse direction relative to the weld direction to examine the HAZ fracture toughness via SENT testing. Prior to machining, the SENT specimen blanks were straightened through a bend flattening procedure (described in Part 2 of the BS7448 Standard (Ref. 41)) to compensate for weld distortion and to preserve as much specimen thickness as possible. The specimens were then machined to a final thickness (B) and width (W) of $10.8 \pm 0.05 \mathrm{~mm}$ as proposed by Shen et al. (Ref. 42). The specimen length (L) was $~ 108 \mathrm{~mm}$ $(\mathrm{L}=10 \mathrm{~W})$, plus additional length to accommodate gripping of the ends with hydraulic wedges. The specimens were surface notched by electrical discharge machining (EDM) from the OD surface and then fatigue precracked (according to ISO 12135:2002/ISO 15653:2010) to target the microstructure of the HAZ, particularly the CGHAZ. The desired initial crack depth was $\mathrm{a}_{0}=0.25 \mathrm{~W}(\mathrm{~W}=\mathrm{B})$.

Due to differences in the constraints at mid-thickness (toward plane strain) and at the sides (plane stress) of the specimen, crack tunneling was expected (Ref. 43). Tunneling degrades the accuracy of the crack growth measurements (Ref. 44). Accordingly, following fatigue precracking, the SENT specimens for J-R curve development were side grooved to a depth of approximately $0.8 \mathrm{~mm}$ on each side (for a total reduction of up to $15 \%$ of the thickness) with a groove radius of approximately $0.25 \pm 0.05 \mathrm{~mm}$ and an angle of $45 \mathrm{deg}$. As such, the net thickness, $\mathrm{B}_{\mathrm{N}}$, was equal to 0.85 B. Side grooving was conducted to minimize final crack curvature by generating relatively uniform constraints across the crack tip. The geometry of the SENT specimen is shown in Fig. 2B.
Figure $3 \mathrm{~A}$ and $\mathrm{B}$ show macrographs of samples welded using cold-wire TSAW and TSAW processes, respectively, indicating the position of the initial crack. Figure $3 C$ and D depict a side and top macroview, respectively, of the final notched SENT specimen including side grooves. The SENT tests were conducted at three different temperatures, i.e., room temperature (RT), $-5^{\circ}$ and $-30^{\circ} \mathrm{C}$. For the colder temperatures, the specimens were cooled by circulating ethanol through a small chamber containing the specimen length between the grip faces. The flow rate of ethanol was varied within the chamber to control the testing temperature at $-5^{\circ}$ and $-30^{\circ} \mathrm{C}$. The instantaneous temperature at the vicinity of the crack tip was measured using a thermocouple. For testing at low temperature, the temperature was kept at $-30 \pm 3^{\circ} \mathrm{C}$ according to E1820 Standard through a distance of at least $\pm 2 \mathrm{~B}$ from the notch. To restrict all rotational degrees of freedom during SENT testing, the specimens were clamped using hydraulic grips. A SENT specimen was then loaded/unloaded/reloaded under displacement control with a displacement rate of $0.01 \mathrm{~mm} / \mathrm{s}$, representing quasistatic conditions. The methodology of the loading/ unloading cycles has been adopted from the recommended practice by CanmetMaterials (Ref. 7).

At the initial stage of the test, some loading/unloading cycles were carried out to calculate the initial crack size prior to the initial elastic part of the load-CMOD (crack mouth opening displacement) test. Then, the calculated value was compared with the measured initial crack size, $\mathrm{a}_{0}$. The load varied between $0.25 \mathrm{P}_{\mathrm{Y}}$ and $0.5 \mathrm{P}_{\mathrm{Y}}$ for the initial load/unload cycles. Afterward, six unloading cycles were performed in the elastic regime with an applied force, $\mathrm{P}_{\mathrm{Y}}$, equal to

$$
P_{Y}=\frac{\sigma_{y s}+\sigma_{u t s}}{2}(W-a) B_{e}
$$

where $\sigma_{y s}$ and $\sigma_{u t s}$ are the yield strength and ultimate tensile strength of the specimen, respectively. $W$ and $B_{e}$ are the specimen width and the effective specimen width, respectively, and $a$ is the crack length of the SENT specimen. The effective specimen width, $B_{e}$, is calculated from Equation 2:

$$
B_{e}=B_{N}\left(2 B-B_{N}\right) / B
$$

where $B_{N}$ is the net thickness of the side grooved specimen $(0.85 \mathrm{~B})$. The $\sigma_{y s}$ and $\sigma_{u t s}$ values of the CGHAZ were determined using microhardness testing. According to Cheng (Ref. 45), the relationship between the hardness and the 


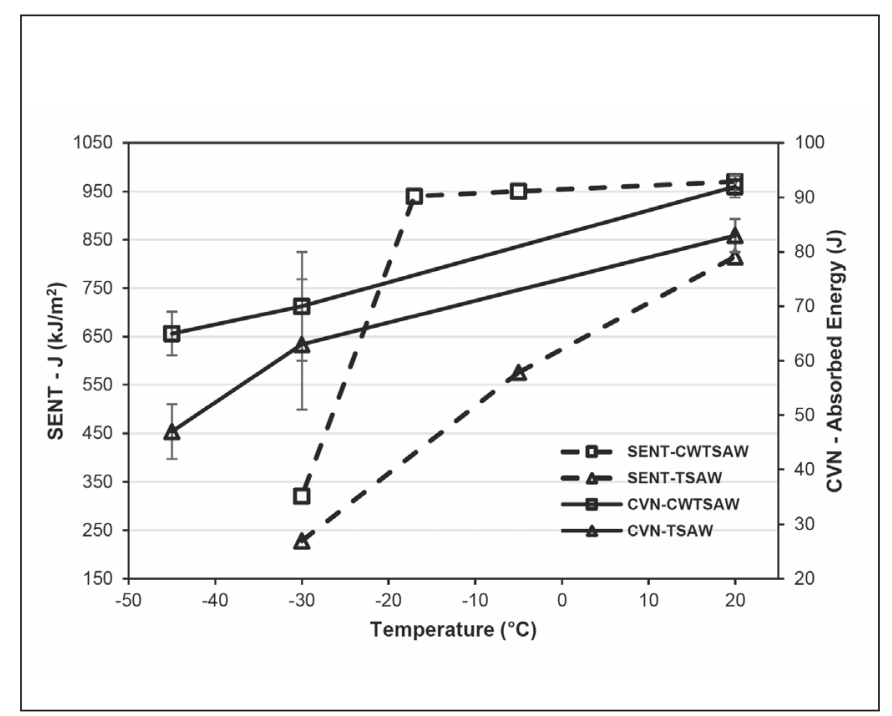

Fig. 4 - Charpy absorbed energy and J-value of the CGHAZ for steel samples welded by TSAW and cold-wire TSAW processes. Dashed lines and solid lines represent the SENT and CVN test results, respectively.

yield strength was empirically determined based on analysis of the dimensions of the indentations. In addition, one empirical equation is widely used in the literature, $\sigma_{y s}=\mathrm{HV} / 0.3$, which approximates the relationship between the hardness $\mathrm{HV}$ and the yield strength. A relationship has been developed for welded C-Mn steels (ISO 15653 Standard (Ref. 46)) that can be used to estimate the $\sigma_{y s}$ (in the range of $160 \mathrm{HV}$ to $495 \mathrm{HV}$ ) and $\sigma_{u t s}$ (in the range of 100 to $400 \mathrm{HV}$ ) of the steel based on the Vickers hardness (HV) value, as follows:

$$
\begin{aligned}
& \sigma_{y s}(M P a)=3.28 H V-221 \\
& \sigma_{U T S}(M P a)=3.3 H V-8
\end{aligned}
$$

According to Equations 3 and 4, the $\sigma_{y s}$ and $\sigma_{u t s}$ values of the CGHAZ of the TSAW and cold-wire TSAW specimens are 559 and $776 \mathrm{MPa}$, and 520 and $737 \mathrm{MPa}$, respectively, for the corresponding microhardness values of 237.8 HV0.5 (TSAW weld) and 225.9 HV0.5 (cold-wire TSAW weld). After the elastic unloading cycles, plastic unloading cycles were performed with CMOD intervals of 0.02 and $0.04 \mathrm{~mm}$ for the first five unloading cycles and the subsequent unloading cycles, respectively. In the unloading compliance method, a monotonically increasing relation between crack depth and compliance is assumed. Accordingly, the specimen is initially unloaded and reloaded at predefined intervals of CMOD, as described above, to evaluate the compliance during the test. The compliance is defined as the slope of a linear regression line through the unloading data set.

In addition to SENT fracture toughness testing, CVN tests were performed on subsize bars extracted from the weld specimens, with dimensions of $5 \times 10 \times 55 \mathrm{~mm}$, at $\mathrm{RT},-30^{\circ}$ and $-45^{\circ} \mathrm{C}$. At least five Charpy specimens per test condition were machined in the transverse orientation relative to the welding direction according to ASTM E23-12c (Ref. 47). Because of the small size of the HAZ and the bulbous shape of the weld metal (WM) and the HAZ, it was not

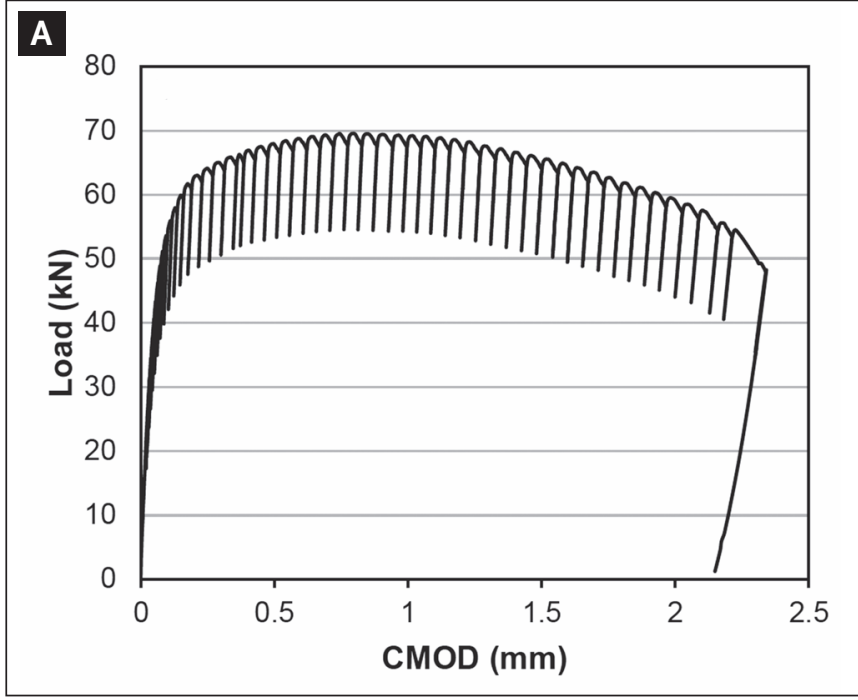

B

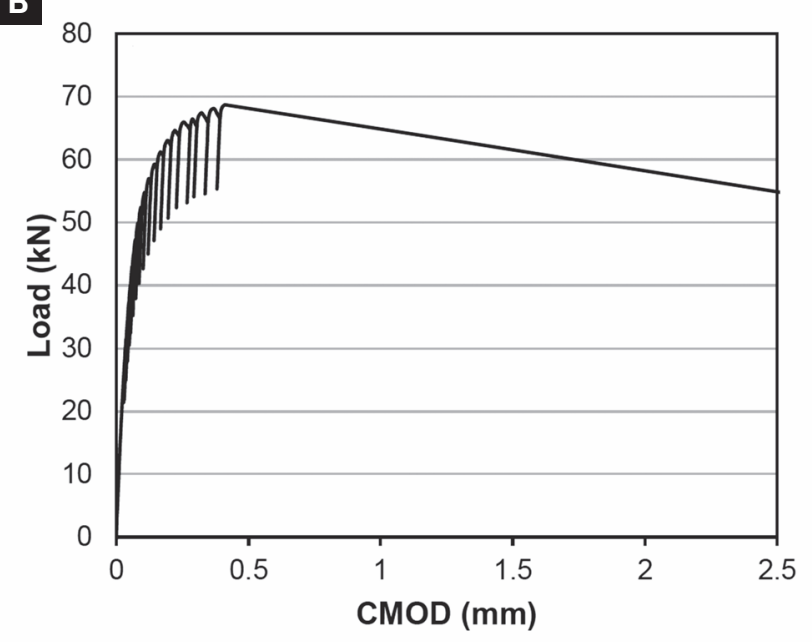

Fig. 5-A typical load vs. CMOD plot for the following: $A-A$ ductile SENT specimen from a cold-wire TSAW weld; $B-a$ brittle SENT specimen from a TSAW weld showing pop-in.

possible to extract full-size Charpy specimens from the HAZ. As such, subsize specimens were extracted as close to the specimen surface as possible to ensure positioning of half of the notch in the CGHAZ and the other half in the fine-grained heat-affected zone (FGHAZ). Figure $2 \mathrm{C}$ illustrates the location of the notch for the Charpy samples.

\section{Microstructural Analysis}

The TEOM technique was utilized to analyze the formation of microstructural features, particularly PAG size and M-A constituents, in the HAZ of the weld samples (Ref. 48). For this purpose, a chemical solution containing $4 \mathrm{~g}$ of picric acid in 96-mL ethanol, along with a few drops of $\mathrm{HCl}$ acid, was prepared to clearly reveal the PAG boundaries. The mean lineal intercept method (ASTM E112 (Ref. 49)) was used to investigate the PAG size in the CGHAZ. Freshly polished specimens were then tint etched through a separate process using modified LePera's etchant for 30-50 s to reveal different mi- 

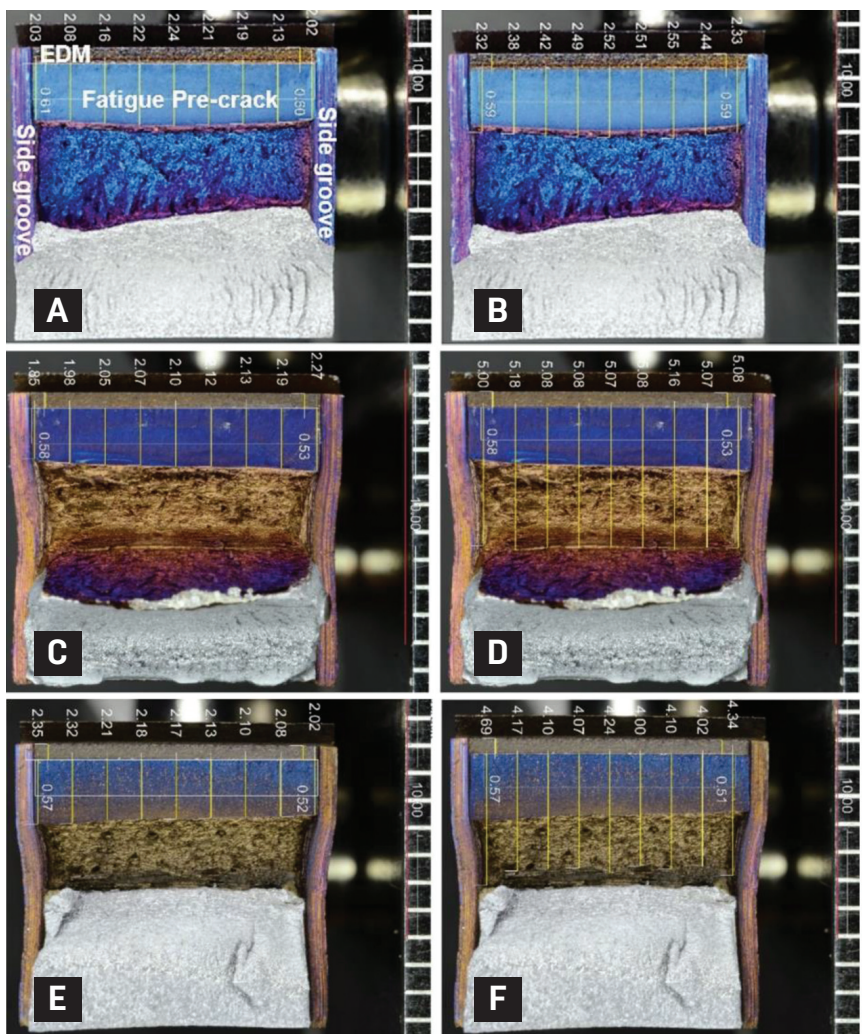
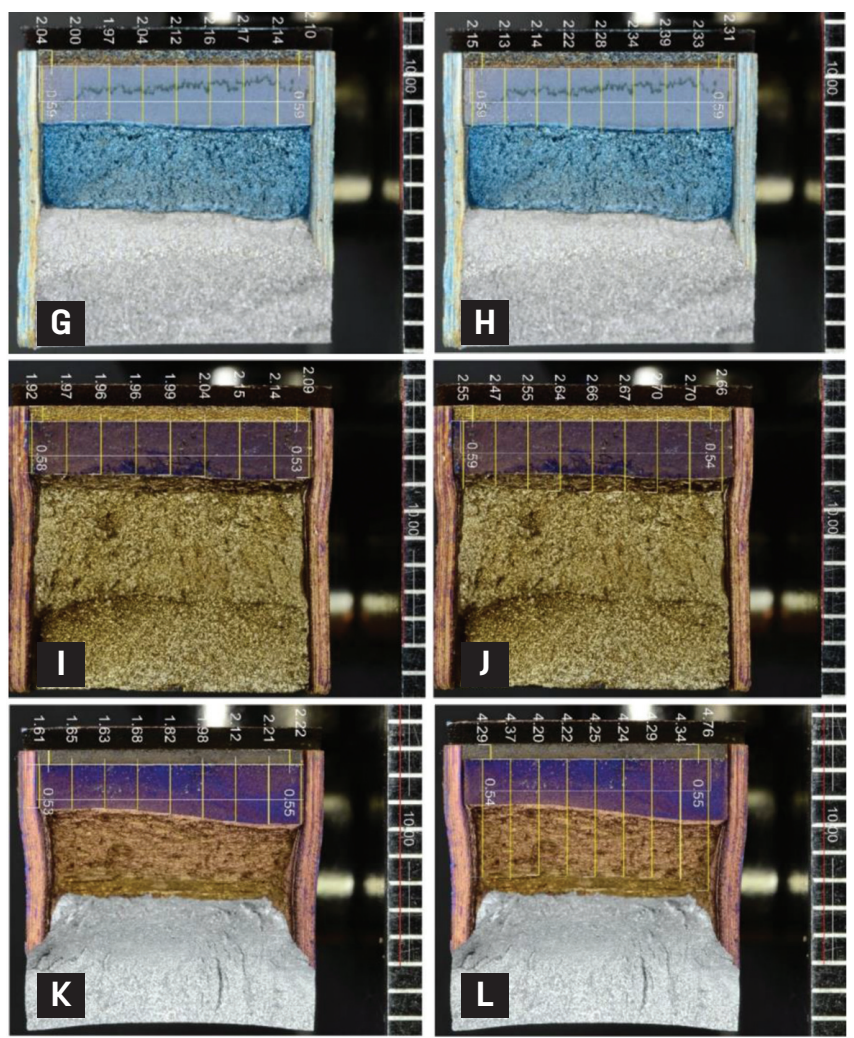

Fig. 6 - Optical macrographs of the fracture surfaces of SENT specimens after testing as follows: $A, B--30^{\circ} C ; C, D--5^{\circ} \mathrm{C}$; and $E, F-R T$ for cold-wire TSAW weld samples; $G, H--30^{\circ} \mathrm{C}$; I, J- $-5^{\circ} \mathrm{C}$; and $K, L-R T$ for TSAW weld samples. The left column represents the initial crack (fatigue precrack) size measurements and the right column represents the final crack length measurements. The small region on top of each specimen represents the EDM notch, which was machined prior to precracking of the specimens. Small grooves along both sides of each specimen are the side grooves machined on the specimens after precracking and prior to SENT testing.

crostructural features. Quantitative analysis of the various phase fractions formed during welding in the FGHAZ and the CGHAZ was conducted using ImageJ commercial image analysis software according to ASTM E562 (Ref. 50). To evaluate the ferrite/bainite $(\alpha / B)$ grain size variation by cold wire addition, electron backscattered diffraction (EBSD) analysis was conducted on the CGHAZ of the weld samples using a Zeiss Sigma field emission gun SEM, operating at $20 \mathrm{kV}$ and equipped with an HKL EBSD system.

\section{Fracture Toughness Analysis Methodology}

According to fracture mechanics principles, the J-integral is separated into elastic $\left(\mathrm{J}_{\mathrm{el}, \mathrm{i}}\right)$ and plastic $\left(\mathrm{J}_{\mathrm{pl}, \mathrm{i}}\right)$ components (Equation 5) to generate J-R curves (ASTM E1152-87 (Ref. 51)).

$$
J=J_{e l, i}+J_{p l, i}
$$

$J_{e l, i}$ is directly calculated from the stress intensity factor, $\mathrm{K}_{\mathrm{i}}$,

Table 3 - Initial and Final Crack Straightness Assessment*

\begin{tabular}{|c|c|c|c|c|c|c|c|c|}
\hline $\begin{array}{l}\text { Notch } \\
\text { Position }\end{array}$ & $\begin{array}{l}\text { Welding } \\
\text { Process }\end{array}$ & $\begin{array}{c}\text { Test } \\
\text { Temperature } \\
\left({ }^{\circ} \mathrm{C}\right)\end{array}$ & $\begin{array}{c}\text { Average } \\
\text { Initial Crack } \\
\text { Length (mm) }\end{array}$ & $\begin{array}{l}\text { Measurement } \\
\text { Difference, } \\
\text { mm (\% B) }\end{array}$ & $\begin{array}{c}\text { Straightness } \\
\text { Validity }\end{array}$ & $\begin{array}{c}\text { Average } \\
\text { Final Crack } \\
\text { Length (mm) }\end{array}$ & $\begin{array}{l}\text { Measurement } \\
\text { Difference, } \\
\text { mm (\% B) }\end{array}$ & $\begin{array}{c}\text { Straightness } \\
\text { Validity }\end{array}$ \\
\hline \multirow{6}{*}{ CGHAZ } & Cold-Wire & -30 & 2.74 & 0.14 (1.2) & Valid & 3.04 & 0.13 (1.1) & Valid \\
\hline & TSAW & -5 & 2.63 & $0.21(1.8)$ & Valid & 5.65 & $0.11(0.9)$ & Valid \\
\hline & & RT & 2.72 & 0.21 (1.7) & Valid & 4.71 & $0.57(4.7)$ & Valid \\
\hline & & -30 & 2.67 & $0.11(1.0)$ & Valid & 2.84 & 0.13 (1.1) & Valid \\
\hline & TSAW & -5 & 2.58 & $0.11(0.9)$ & Valid & 3.18 & $0.13(1.1)$ & Valid \\
\hline & & RT & 2.42 & 0.36 (3.0) & Valid & 4.87 & 0.47 (3.9) & Valid \\
\hline
\end{tabular}

*ASTM E1820-15 assesses crack straightness based on the maximum difference of all nine physical crack measurements from the average measurement and considers the straightness valid when the maximum difference is less than or equal to $0.05 \mathrm{~B}$. 


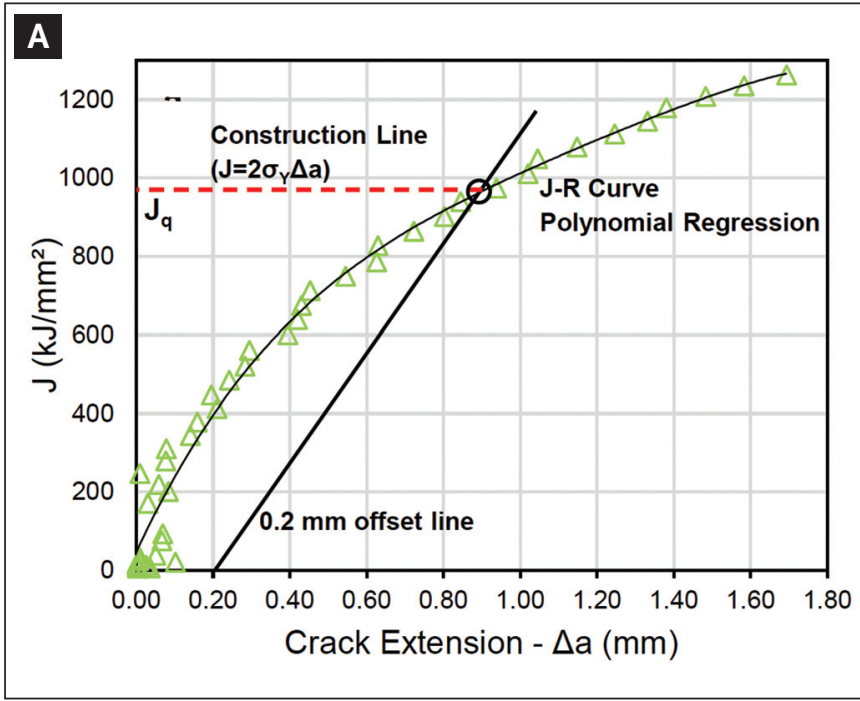

C

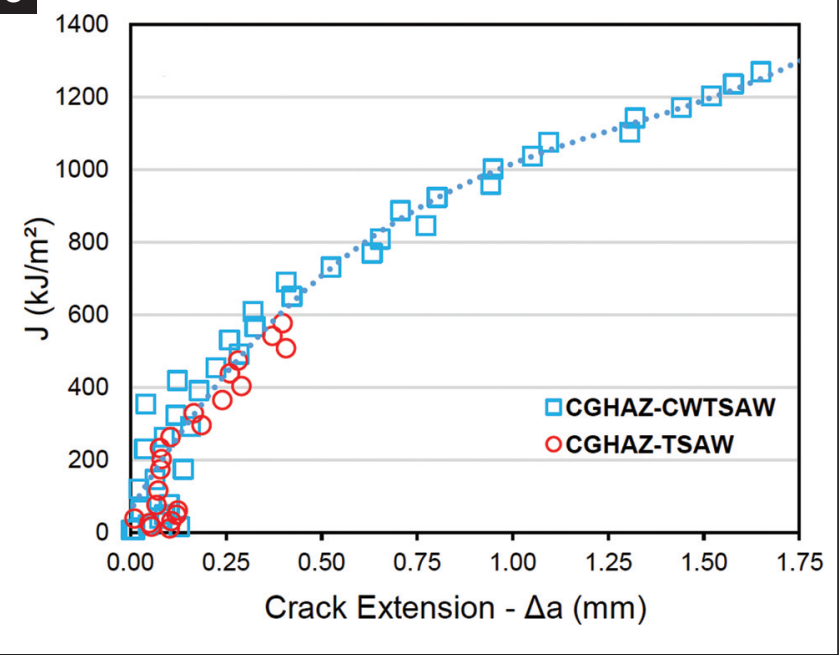

B

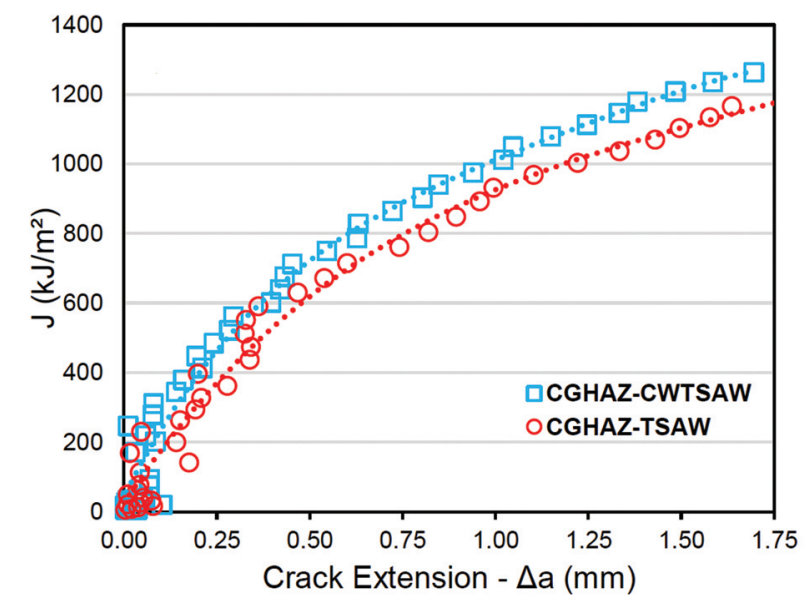

D

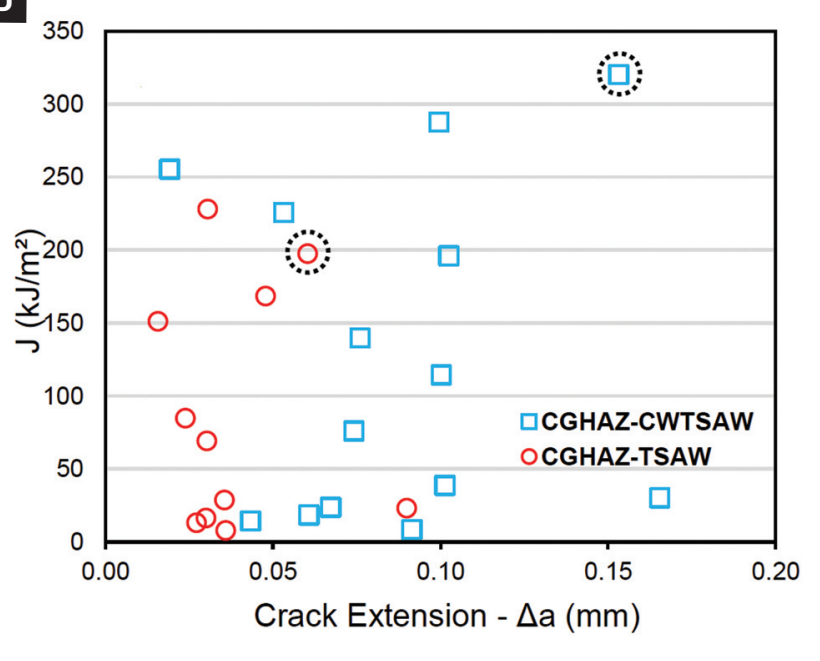

Fig. 7-A - Typical J-R curve indicating the methodology for measuring the $J_{q}$ value from the J-R curve. J-R curves for the CGHAZ of cold-wire TSAW and TSAW specimens at the following: $B-R T$; $C--5^{\circ} \mathrm{C}$; and $D--30^{\circ} \mathrm{C}$.

for a plane strain crack, which is defined in Equation 6.

Equation 7 expresses the relationship for $J_{p l, i}$, which is a

function of the plastic area under the load-CMOD curve.

$$
\begin{aligned}
& J_{p l, i}=\left(J_{p l, i-1}+\frac{\eta_{i-1}^{C M O D}}{B_{N} b_{i-1}}\left(A_{i}^{V_{p l}}-A_{i-1}^{V_{p l}}\right)\right) \\
& \left(1-\frac{\gamma_{i-1}^{L L D}}{b_{i-1}}\left(a_{i}-a_{i-1}\right)\right)
\end{aligned}
$$$$
J_{e l}=\frac{\left(1-v^{2}\right)}{E}\left[\left(\frac{P_{i} \sqrt{\pi a_{i}}}{\sqrt{B B_{N}} W}\right) \times G\left(\frac{a_{i}}{W}\right)\right]^{2}
$$

\begin{tabular}{|c|c|c|c|c|c|}
\hline Notch Position & Welding Process & $\begin{array}{c}\text { Test } \\
\text { Temperature }\left({ }^{\circ} \mathrm{C}\right) \\
\end{array}$ & $\begin{array}{c}\text { Initiation Toughness, } \\
\mathrm{J}\left(\mathrm{kJ} / \mathrm{m}^{2}\right)\end{array}$ & $\begin{array}{c}\text { Toughness } \\
\text { Qualification }\end{array}$ & $\begin{array}{c}J_{m} \\
\left(\mathrm{KJ} / \mathrm{m}^{2}\right)\end{array}$ \\
\hline & Cold-Wire & RT & 966 & $J_{q}$ & 459 \\
\hline & TSAW & -5 & 955 & $J_{q}^{q}$ & 457 \\
\hline & & -30 & 320 & $\mathrm{~J}_{\mathrm{qc}}$ & 320 \\
\hline \multicolumn{6}{|l|}{ CGHAZ } \\
\hline & TSAW & RT & 815 & $\mathrm{~J}_{\mathrm{q}}$ & 474 \\
\hline & & -5 & 576 & $\mathrm{~J}_{\mathrm{qc}}^{\mathrm{a}}$ & 576 \\
\hline & & -30 & 228 & $\mathrm{~J}_{\mathrm{qc}}$ & 228 \\
\hline
\end{tabular}

Table 4 - J-Integral Values for the CGHAZ of Weld Specimens Tested with the SENT Method 

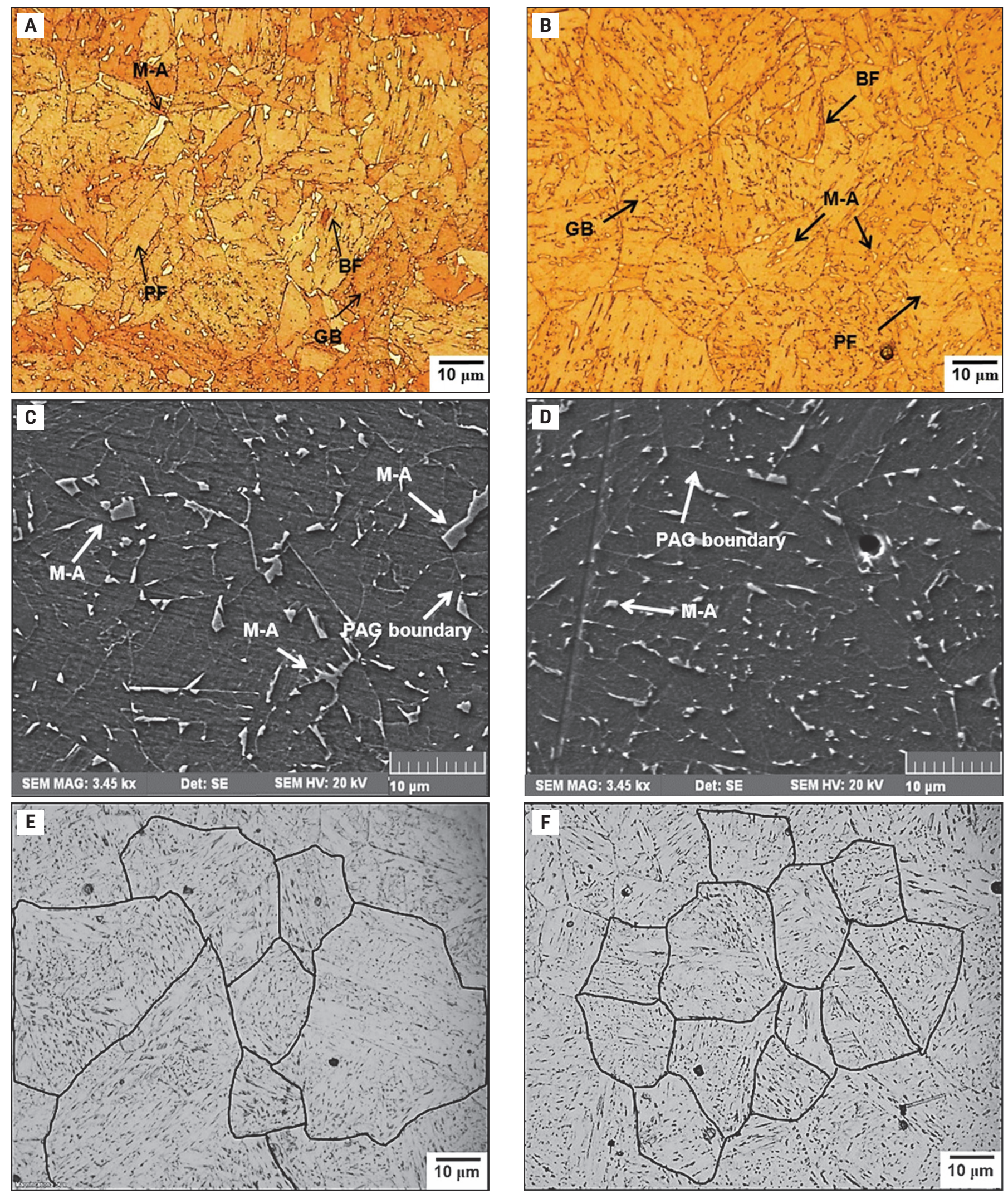

Fig. 8 - Micrographs showing the microstructural features in the CGHAZ of the (A, C) TSAW weld and (B, D) cold-wire TSAW weld. The PAG boundaries in the CGHAZ are highlighted in E and $F$ for the TSAW and cold-wire TSAW weld, respectively. Images A, B, E, and $F$, along with $C$ and $D$, are TEOM and SEM secondary electron (SE) micrographs, respectively. 

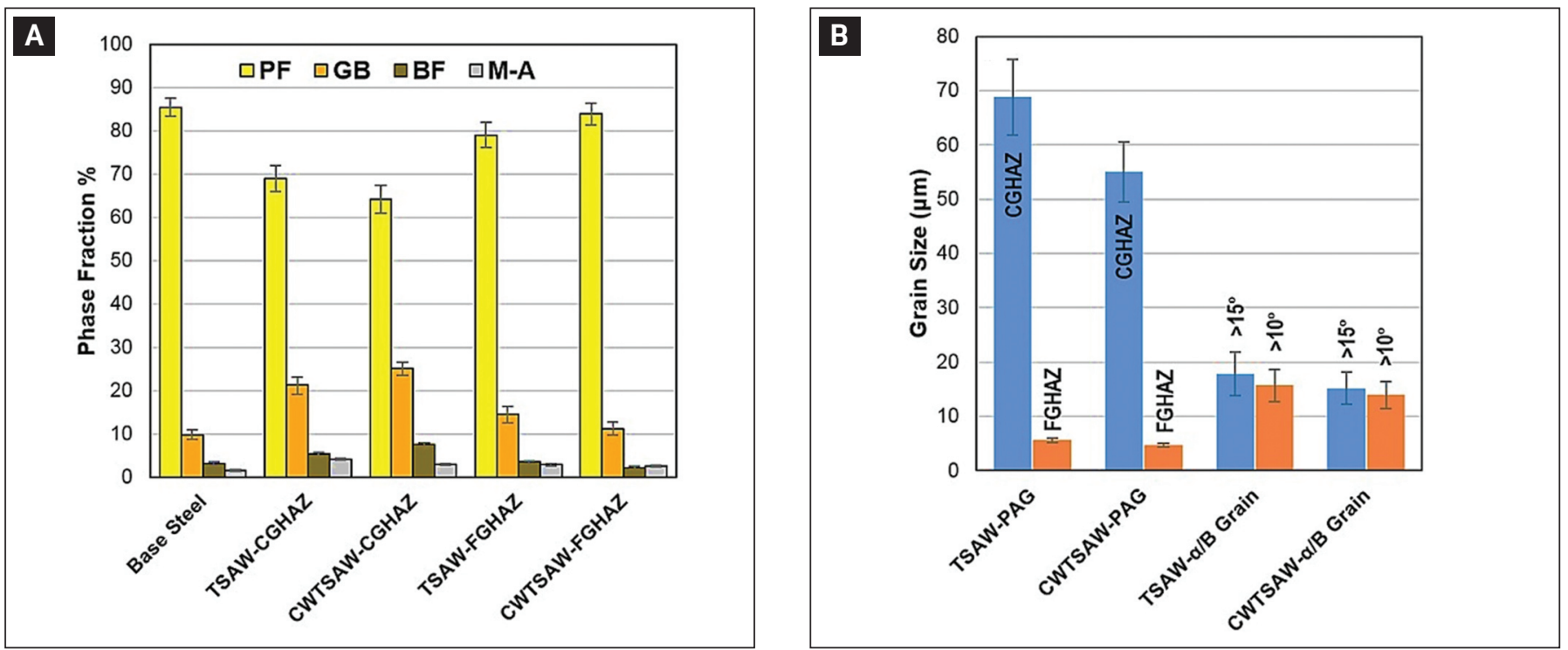

Fig. 9-A - Fraction of microstructural constituents formed in the CGHAZ and FGHAZ; B - PAG and $\alpha / B$ grain size analysis in the CGHAZ of welded X70 microalloyed steels by TSAW and cold-wire TSAW processes.

where $E$ is the Young's modulus, $v$ is Poisson's ratio, $a_{i}$ is the current crack size, and $P_{i}$ is the load at the beginning of the unload/load cycle. $G\left(a_{i} / W\right)$ is a function of the crack size to width ratio, $b_{i}$ is the ligament size $\left(W-a_{i}\right)$ and $A_{p l, i}$ is the plastic area under the load-CMOD curve. The parameters $\eta_{i}{ }^{C M O D}$ and $\gamma_{i}^{L L D}$ have been defined by the finite element analyses conducted by Shen et al. (Ref. 52) under a twodimensional plane strain assumption. These parameters are defined separately in the Appendix at the end of this paper. Equation 8 was developed to determine the crack size based on CMOD elastic compliance $\left(C_{i}\right)$ measurements via finite element analysis. The equation is valid for $\mathrm{a} / \mathrm{W}$ ratios in the range of 0.05 to 0.95 .

$$
\frac{a_{i}}{W}=\sum_{i=1}^{10} \frac{r_{i}}{\sqrt{B_{e} C_{i} E}+1}
$$

According to the ISO 12135 Standard, $r_{i}$ is the coefficient of a polynomial least-squares fitting function (Ref. 53), which is defined in the Appendix. It is interesting to note that, according to the formulas mentioned in ASTM E182011 (Refs. 54, 55), the changes in CMOD compliance as a function of a/W for clamped SENT specimens (expressed as $B_{e} C_{i} E$ in Equation 8) are significantly larger than for single edge notched bend (SENB) specimens. The work done by Cravero et al. (Ref. 56) and Joyce et al. (Ref. 57) showed that specimen rotation during SENT testing due to the move- ment of the center of the remaining ligament toward the load line plays a significant role in the crack propagation. Accordingly, the value of elastic compliance given in Equation 8 is corrected according to Equation 9 as follows:

$$
C_{c, i}=\frac{C_{i}}{1-0.165 \frac{a_{0}}{W}\left(\frac{P_{i}}{P_{Y}}\right)}
$$

where $C_{c, i}$ is the compliance after specimen rotation correction, which is established by means of two-dimensional, plane-strain finite element analysis for the SENT specimens with length to width ratio of 10 and $a_{0} / W$ between 0.2 and 0.5. $P_{i}$ and $P_{Y}$ are the load at the beginning of the unload/ load cycle and the load limit, respectively.

\section{Results}

The average CVN impact energy (average of at least five Charpy tests per test condition) at three different temperatures for the weld samples is presented in Fig. 4. The average impact energy was increased by the addition of a cold wire to the conventional TSAW process, with a corresponding reduction in the heat introduced to the weldment. Due to the proximity of the test temperature at $-30^{\circ} \mathrm{C}$ to the ductile-tobrittle transition temperature (DBTT) for this type of steel (i.e., $-30^{\circ} \mathrm{C}$ ), large error bars for the CVN impact energy of the HAZ weld samples were observed. Shome et al. (Ref. 25)

Table 5 - Characteristics of M-A Constituents in the CGHAZ of Different Welds

Weld Sample

Fraction (vol-\%)

Mean Size $(\mu \mathrm{m})$

Interspacing $(\mu \mathrm{m})$

Cold-Wire TSAW

TSAW

$3.0 \pm 0.1$

$0.3 \pm 0.02$

$0.48 \pm 0.03$

$2.5 \pm 0.1$

$4.9 \pm 0.2$ 

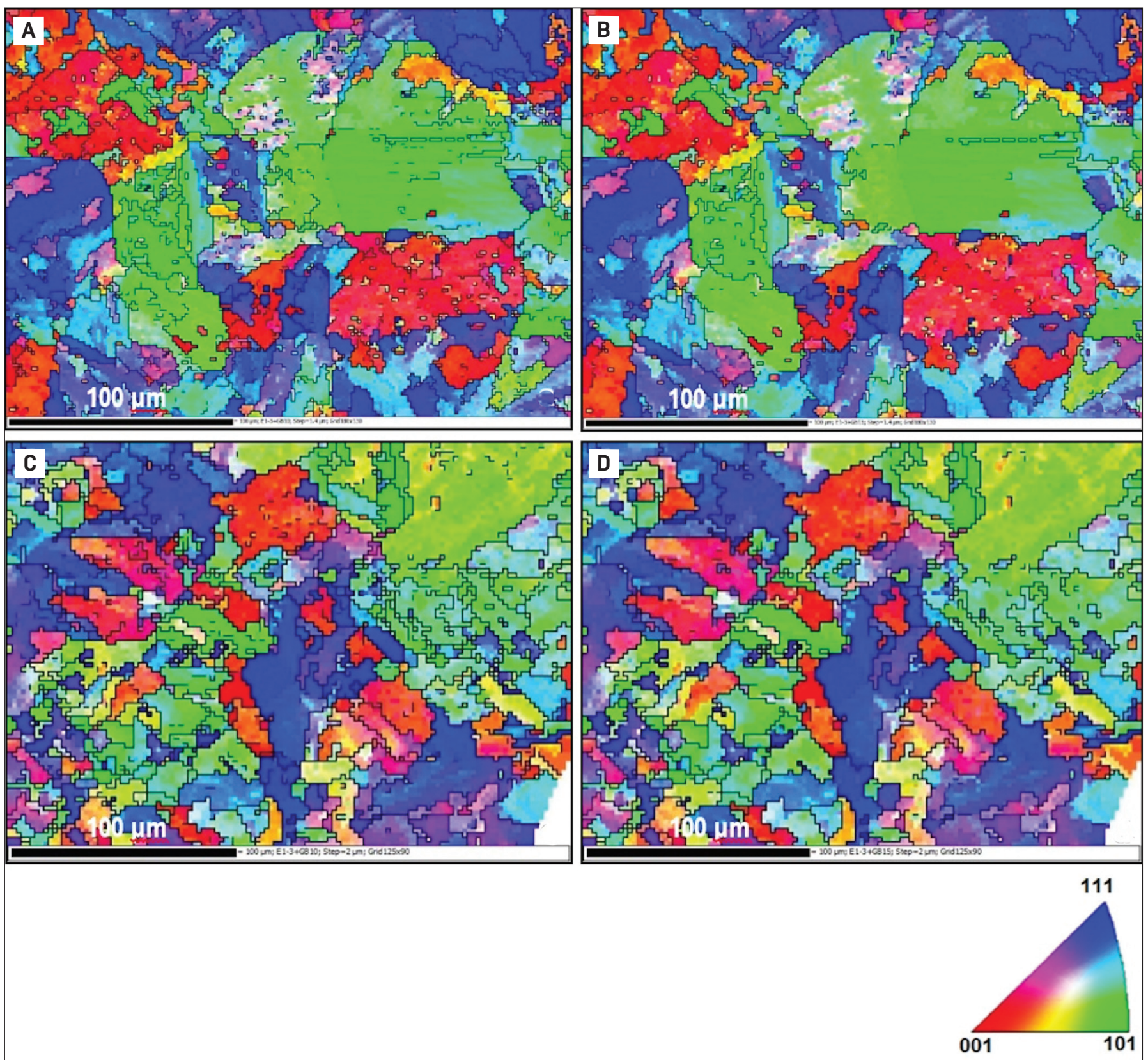

Fig. 10 - EBSD maps showing $\alpha / B$ grains based on boundaries with these angles: $A, C \rightarrow 10$ deg; $B, D->15$ deg in the CGHAZ of $(A, B)$ TSAW and $(C, D)$ cold-wire TSAW samples.

reported that the Charpy energy for ferritic steels commonly exhibits large scatter in the DBTT region.

Figure 5A and B depict typical load-displacement curves for a fully ductile specimen (e.g., RT test specimen) and a specimen with brittle fracture (e.g., $-30^{\circ} \mathrm{C}$ test specimen). The pop-in phenomenon (Fig. 5B) is typically observed for load-displacement curves of brittle materials (an interruption in the load-displacement at relatively low displacements) and is due to brittle instability of the specimen (Ref. 58). The CMOD compliance relationships developed by CanmetMaterials for SENT specimens (Refs. 55, 56) were used to generate J-R curves by regression of the load-displacement data. However, prior to calculation of the J-R curves from the load-CMOD plots, it was essential to assess the straightness of the initial fatigue precrack and the final crack during SENT testing for a sufficient estimation of the toughness. For this reason, according to ASTM E1820-11 procedures, the assessment of the initial and final crack straightness was conducted, and the specimens were sectioned to ensure the crack propagated in the HAZ, particularly the CGHAZ.

According to the standard, the SENT specimens were sectioned at cryogenic temperatures and heat tinted and then nine physical crack measurements were performed. The crack straightness was evaluated based on the maximum difference of the nine crack length measurements from the av- 
erage value. As per Section 9.1 of the standard, the crack straightness was considered valid if the maximum difference was $\leq 0.05$ B. Figure 6 shows macrographs of the fracture surface of the SENT tested weld samples indicating the EDM notch and the length of the initial and final crack. Crack straightness assessment and average length of the initial and final cracks are summarized in Table 3 .

The J-R curves for weld samples tested in the CGHAZ at RT, $-5^{\circ}$ and $-30^{\circ} \mathrm{C}$ are shown in Fig. 7. A typical J-R curve indicating the methodology of measuring J-integral values from the J-R curve (Refs. 59, 60) is shown in Fig. 7A. Initially, a construction line, with a slope that was a function of the yield and ultimate tensile strengths of the material and the crack extension was drawn. This was followed by drawing an offset line parallel to the construction line at $0.2 \mathrm{~mm}$ offset.

$\mathrm{J}_{\mathrm{q}}$ is the J-integral at the onset of ductile tearing $(0.2 \mathrm{~mm}$ offset) according to ASTM E1820-11 Annex A9 (Refs. 54, 55). $\mathrm{J}_{\mathrm{q}}$ and $\mathrm{J}_{\mathrm{m}}$ (J-integral at the maximum load) or $\mathrm{J}_{\mathrm{qc}}(\mathrm{J}-$ integral at pop-in with less than $0.2 \mathrm{~mm}$ of prior ductile tearing) values for SENT testing in the CGHAZ of the weld specimens are presented in Table $4 . \mathrm{J}_{\mathrm{q}}$ was measured as the fracture toughness for the specimens with ductile fracture; however, for specimens with a brittle fracture mode, $\mathrm{J}_{\mathrm{qc}}$ and/or $\mathrm{J}_{\mathrm{m}}$ were considered as the fracture toughness values because there was not sufficient data in the J-R curves for evaluation of $\mathrm{J}_{\mathrm{q}}$. The large scatter in the J-R curves for weld specimens tested at $-30^{\circ} \mathrm{C}$ was primarily due to the brittle behavior of the specimen at this temperature. According to the J-integral results shown in Fig. 4, there is an increase in the $\mathrm{J}$ value at the three different test temperatures through the addition of a cold wire to the conventional TSAW process, with a corresponding reduction in the heat introduced to the weldment. The trend in the J-integral values for the CGHAZ of the cold-wire TSAW samples relative to the TSAW samples correlates with the CVN test results.

As stated earlier, the fracture toughness in the CGHAZ was influenced by the microstructural changes taking place during welding as a result of the thermal cycle the steel experiences. The microstructure of the base X70 steel was predominantly polygonal ferrite (PF - 85.5\%) and granular bainite (GB - 9.8\%), with a small fraction of bainitic ferrite (BF-3.2\%) and M-A constituents (1.5\%). However, the TEOM (Fig. 8A and B) and SEM (Fig. 8C and D) images indicate the microstructure was significantly altered in the CGHAZ. The shape, size, and fraction of the M-A constituents in the CGHAZ were changed by cold wire addition and the consequent variation in the welding heat input. The phase amounts formed in the CGHAZ and FGHAZ are shown in Fig. 9A. Because no significant changes in the microstructure of the FGHAZ were observed, the micrographs are not shown here.

In addition to the phase transformations taking place in the CGHAZ, the PAG and ferrite/bainite grain size were reduced by the additional cold wire. Micrographs highlighting the PAG boundaries using the TEOM technique and the ferrite/bainite grain boundaries via EBSD are shown in Fig. 8E and F and Fig. $10 \mathrm{~A}-\mathrm{D}$, respectively. Individual ferrite/bainite grains were identified either as having boundary angles greater than 10 deg or greater than 15 deg. A 10-15 deg misorientation of two neighboring grains was considered as the transition from lowangle to high-angle grain boundaries. The average of at least

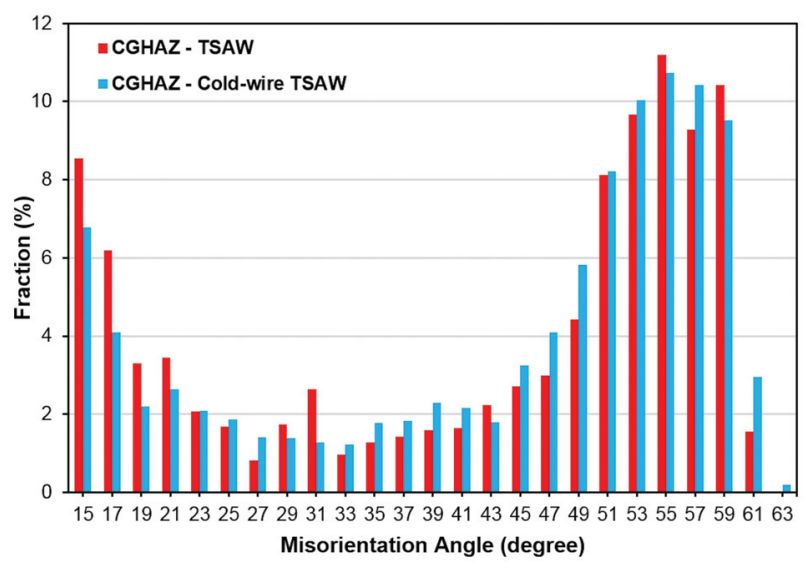

Fig. $11-$ The $\alpha / B$ boundary misorientation angle distribution in the CGHAZ of microalloyed steel welded by the cold-wire TSAW and conventional TSAW processes.

five grain size measurements conducted on the TEOM and EBSD micrographs is shown in Fig. 9B. These alterations in grain size and microstructural features were attributed to a reduction in the heat introduced to the steel and, consequently, a decrease in the retention time in the austenitic region, i.e., $1100^{\circ}-1400^{\circ} \mathrm{C}$, and an increase in the cooling rate, which are discussed in detail in the next section.

\section{Discussion}

The addition of a cold wire to the conventional TSAW process resulted in an increase in the absorbed impact energy and J-value of the CGHAZ obtained by CVN and SENT testing, respectively. The heat input and the thermal cycle that the steel experiences during welding essentially governs the variations in fracture toughness values for the HAZ of welded microalloyed steel (Ref. 29). In addition, property changes in the CGHAZ were attributed to the alterations in the PAG size and the fraction and morphology of the microstructural features, particularly the M-A constituent, which are directly influenced by the heat introduced to the steel. Considering the fact the characteristics of the M-A constituents (as the key microstructural feature formed in the CGHAZ of microalloyed steels) govern both the crack initiation and propagation stages, a similar trend was observed in the SENT and CVN toughness test results.

According to the TEOM and SEM micrographs of the CGHAZ, shown in Fig. 8, the PAG size in the CGHAZ was decreased by addition of the cold wire. The reduction in the PAG size in the CGHAZ from $68 \mu \mathrm{m}$ (TSAW weld) to $55 \mu \mathrm{m}$ (coldwire TSAW weld) was attributed to a reduction in the heat introduced to the weldment and, consequently, a reduction in the retention time in the austenitization temperature range $\left(1100^{\circ}-1400^{\circ} \mathrm{C}\right)$ and an increase in the cooling rate by feeding a cold wire to the welding process. An analysis of the heat input, based on the thermodynamic principles, which is discussed in Ref. 61, indicated the heat input of the cold-wire TSAW process was reduced by $9 \%$ relative to the TSAW 
process with a corresponding increase in the cooling rate by $10 \%$. According to Fig. 8, the CGHAZ microstructure of the TSAW sample (with higher heat input) is made up of large PAGs, PF, GB, BF, and large M-A constituents. In contrast, the CGHAZ microstructure of the cold-wire TSAW sample (with lower heat input) is composed of finer PAGs, PF, GB, and BF associated with fine, blocky shaped M-A constituents. Phase fraction analysis (Fig. 9) showed less M-A is formed within the CGHAZ of the cold-wire TSAW weld sample compared with the TSAW sample. However, in addition to the fraction and shape, the size and interspacing of M-A constituents in the CGHAZ of the weld samples play a significant role in the fracture toughness.

Table 5 indicates the characteristics of the M-A constituents formed in the CGHAZ of the two weld specimens. The fraction of M-A constituents in the CGHAZ was reduced as a consequence of PAG size reduction (Refs. 23, 24) by the cold wire addition. Quantitative analysis of the $\mathrm{M}-\mathrm{A}$ regions indicates the fraction of M-A constituents in the CGHAZ with sizes larger than $2 \mu \mathrm{m}$ for the TSAW and cold-wire TSAW samples is $3.2 \pm 0.2 \%$ and $1.0 \pm 0.1 \%$, respectively. The size analysis indicates there is a reduction in the M-A size with a corresponding reduction in $\mathrm{M}$-A spacing upon the addition of a cold wire. The M-A interparticle spacing was determined using the equation developed by Somekawa (Ref. 62).

The larger M-A constituents in the CGHAZ of the TSAW sample were due to the higher martensite start temperature (Ms), which correlates with the larger PAGs (Refs. 28, 63). Bhadeshia (Ref. 64), Heinze et al. (Ref. 65), and Guimaraes (Ref. 66) suggested that a decrease in Ms temperature correlates with a decrease in the PAG size, which results in a lower volume fraction of martensite. According to Koistinen and Marburger (Ref. 67) and Fisher et al. (Ref. 68), the fraction of martensite is a function of the amount of undercooling below the Ms temperature. As such, the volume fraction of martensite, which was formed in the early stages of the austenite transformation, was proportional to the PAG size cubed. As such, "for a larger PAG, the fraction of the transformation needed to detect Ms is reached at a smaller undercooling" (Ref. 63). Therefore, the fraction and size of formed M-A constituent increased for a coarser PAG size. In this regard, the work done by Li et al. (Ref. 23) and Yu et al. (Ref. 24) showed that a microstructure comprised of coarse PAGs and coarse M-A constituents promotes brittle fracture in the CGHAZ. As such, both grain size refinement and the $\mathrm{M}-\mathrm{A}$ transformation concurrently play a significant role in the HAZ toughness of welded microalloyed steels.

Due to the increased transformation of austenite to the M-A constituent, a higher proportion of localized brittle zones, i.e., the M-A constituents, was formed in the CGHAZ of the TSAW sample relative to that of the cold-wire TSAW sample, which resulted in higher microhardness values in the CGHAZ for the TSAW sample (237.8 $\pm 5.5 \mathrm{HV0.5})$ relative to the cold-wire TSAW sample (225.9 \pm 4.5 HV0.5). Moreover, a finer distribution of small M-A constituents within the ferritic matrix of the CGHAZ of the cold-wire TSAW sample resulted in higher J-integral values and Charpy energies at different test temperatures. The M-A constituent was significantly harder than the internal grain microstructure, so that cracks initiate easily at the M-As.
However, large slender shaped M-A constituents formed in the CGHAZ of the TSAW sample can contribute more as crack initiation sites and promote the propagation of microcracks due to the relatively higher stress concentration at the elongated M-A constituents. The fine M-A constituents with small interspacing formed in the CGHAZ of the coldwire TSAW sample can slow down, if not arrest, any cracks initiated at one of the M-A constituents from further propagation. The work done by Davis et al. (Ref. 21) and Reichert et al. (Ref. 69) also confirm that the slender M-A constituents are the most detrimental to fracture toughness.

In addition to the formation of M-A constituents, the ferrite/bainite grain size affects the properties of the CGHAZ of welded microalloyed steels. Low angle boundaries (smaller than 10-15 deg) are not effective obstacles for crack propagation and, as a result, do not significantly contribute to the toughness. High angle grain boundaries (larger than 10-15 deg), on the other hand, have a greater effect on properties (Refs. 70-72). Accordingly, 10- and 15-deg thresholds were chosen as the criteria for the EBSD mapping of ferrite/bainite grains - Fig. 10. Although the ferrite/bainite grains in the CGHAZ were significantly coarser than those in the base X70 microalloyed steel $(4.1 \pm 0.5 \mu \mathrm{m})$, the addition of a cold wire at a rate of $25.4 \mathrm{~cm} / \mathrm{min}$ reduced the grain size (grains with boundary angles larger than $15 \mathrm{deg}$ ) in the CGHAZ from $17.6 \pm 5.0 \mu \mathrm{m}$ (TSAW weld) to $15.3 \pm$ $4.5 \mu \mathrm{m}$ (cold-wire TSAW weld). The misorientation angle distribution of the ferrite/bainite boundary ( $\geq 15 \mathrm{deg}$ ) in the CGHAZ of the two welds is shown in Fig. 11. Although more grains with boundary angles smaller than 31 deg formed in the CGHAZ of the TSAW weld, a relatively higher fraction of grains formed with boundary angles greater than 31 deg in the CGHAZ of the cold-wire TSAW weld. Because a larger grain boundary angle generally has a greater effect on the fracture toughness, the grains formed in the CGHAZ of the cold-wire TSAW weld are likely to provide more barriers to crack propagation in the CGHAZ relative to the CGHAZ of the TSAW weld. As such, in addition to the reduction in the fraction of M-A constituents and the refinement in the morphology of M-A constituents, the addition of a cold wire (which lowers the welding heat input) resulted in grain size refinement due to the lower peak temperature and faster cooling rate in the CGHAZ. These two metallurgical factors provided an improvement in the HAZ fracture toughness.

\section{Conclusions}

The influence of a recently developed welding process, i.e., tandem submerged arc welding with additional cold wire (coldwire TSAW), on the microstructure and fracture toughness of an X70 microalloyed steel was evaluated. Single-edge notched tension (SENT) and the Charpy V-notch (CVN) impact tests indicated the fracture toughness of the coarse-grained heataffected zone (CGHAZ) was improved by a cold wire addition into the welding process. The cold wire addition primarily led to a reduction in the prior austenite grain (PAG) size in the CGHAZ. However, microstructural evaluation indicated the fraction, size, and interspacing of martensite-austenite (M-A) constituents in the CGHAZ were reduced, and the shape was altered from slender to blocky when a cold wire was fed into the TSAW process. Furthermore, ferrite/bainite grains were 
refined in the CGHAZ by addition of the cold wire. A combination of relatively large PAGs and ferrite/bainite grains, and large elongated M-A constituents, which were mostly formed along the boundaries in the CGHAZ of the TSAW samples, was responsible for the inferior toughness properties in the HAZ relative to the cold-wire TSAW samples. The formation of larger M-A constituents in the CGHAZ can stimulate the formation of microcracks, which lead to intergranular fracture.

\section{Acknowledgments}

The authors would like to acknowledge the Natural Sciences and Engineering Research Council (NSERC) of Canada, Evraz Inc. NA, TransCanada PipeLines Ltd., and Enbridge Pipelines Inc. for their financial support. The assistance of Jonas Valloton with EBSD is appreciated. SGS Ludwig Canada and the R\&D Division of Evraz Inc. NA are also recognized for technical assistance in conducting SENT testing and CVN testing, respectively.

\section{References}

1. Moeinifar, S. 2011. Microstructure and toughness properties of subcritically, intercritically and supercritically heat affected zones in X80 microalloyed pipeline steel. Adv. Mater. Res.: 383-390, 5886-5893. DOI: 10.4028/www.scientific.net/AMR.383-390.5886

2. Kimura, H., Yokota, N., TomoyukiIshikawa, Kakihara, S., Kondo, J., and Yokota, T. 2016. Development of grade X80 high charpy energy linepipe by MA formation control. $11^{\text {th }}$ Int. Pipeline Conf. American Society for Mechanical Engineers pp. 1-6.

3. Ju, J.-B., Kim, W., and Jang, J. 2012. Variations in DBTT and CTOD within weld heat-affected zone of API X65 pipeline steel. Mater. Sci. Eng. A 546: 258-262. DOI: http://dx.doi.org/10.1016/ j.msea.2012.03.062

4. McCabe, D. E. 1972. Evaluation of the compact tension specimen for determining plane-strain fracture toughness of high strength materials. J. Mater. Sci. 7: 449-542.

5. Zhu, X.-K. 2016. Review of fracture toughness test methods for ductile materials in low-constraint conditions. Int. J. Press. Vessel. Pip.: 139, 140, 173-183.

6. Det-Norske-Veritas. 2006. Control for pipeline installation methods introducing cyclic plastic strain.

7. Canmet Materials. 2010. Recommended practice: Fracture toughness testing using $\mathrm{SE}(\mathrm{T})$ samples with fixed-grip loading.

8. Park, D.-Y., Gravel, J.-P., Arafin, M., Liang, J., and Hari Manoj Simha, C. 2014. Evaluation of two low-constraint toughness test methods in a single specimen. J. Eng. Mater. Technol. 137: 11003. DOI: http://dx.doi.org/10.1115/1.4028728

9. ExxonMobil. 2010. Measurement of crack tip opening displacement (CTOD) - Fracture resistance curves using single-edge notched tension (SENT) specimens.

10. Park, D.-Y., Gravel, J. P., Arafin, M., Liang, J., and Hari Manoj Simha, C. 2015. Evaluation of two low-constraint toughness test methods in a single specimen. J. Eng. Mater. Technol. 137: 011003-1-011003-9. DOI: 10.1115/1.4028728

11. Koo, J. Y., Luton, M. J., Bangaru, N. V., Petkovic, R. A., Fairchild, D. P., Petersen, C. W., Asahi, H., Hara, T., Terada, Y., Sugiyama, M., Tamehiro, H., Komizo, Y., Okaguchi, S., Hamada, M., Yamamoto, A., and Takeuchi, I. 2004. Metallurgical design of ultra high-strength steels for gas pipelines. Int. J. Offshore Polar Eng. 14: 2-10.

12. Tamehiro, H., Asahi, H., Hara, T., Terada, Y., Luton, M. J., and Koo, J. 2001. Ultra-high strength, weldable steels with excellent ultra-low temperature toughness. ExxonMobil Upstream Research Co. Houston, Tex., Nippon Steel Corp., Tokyo, Japan.

13. Honeycombe, R. W. K., and Bhadeshia, H. K. D. H. 1996. Steels: Microstructure and Properties, Metallurgy and Materials Science Series. Edward Arnold, London, Great Britain.

14. Li, C., Wang, Y., and Chen, Y. 2011. Influence of peak temperature during in-service welding of API X70 pipeline steels on microstructure and fracture energy of the reheated coarse grain heat-affected zones. J. Mater. Sci. 46: 6424-6431. DOI: 10.1007/ s10853-011-5592-7

15. Silwal, B., Li, L., Deceuster, A., and Griffiths, B. 2013. Effect of postweld heat treatment on the toughness of heat-affected zone for grade 91 steel. Welding Journal 93: 80-s to 87-s.

16. Lambert, A., Drillet, J., Gourgues, A. F., Sturel, T., and Pineau, A. 2000. Microstructure of martensite-austenite constituents in heat affected zones of high strength low alloy steel welds in relation to toughness properties. Sci. Technol. Weld. Join. 5: 168-173. DOI: 10.1179/136217100101538164

17. Moeinifar, S., Kokabi, A. H., and Hosseini, H. R. M. 2011. Effect of tandem submerged arc welding process and parameters of Gleeble simulator thermal cycles on properties of the intercritically reheated heat affected zone. Mater. Des. 32: 869-876. DOI: 10.1016/j.matdes.2010.07.005

18. Moeinifar, S., Kokabi, A. H., and Hosseini, H. R. M. 2011. Role of tandem submerged arc welding thermal cycles on properties of the heat affected zone in X80 microalloyed pipe line steel. J. Mater. Process. Technol. 211: 368-375. DOI: 10.1016/ j.jmatprotec.2010.10.011

19. Gharibshahiyan, E., Honarbakhsh, A., Parvin, N., and Rahimian, M. 2011. The effect of microstructure on hardness and toughness of low carbon welded steel using inert gas welding. Mater. Des. 32: 2042-2048. DOI: 10.1016/j.matdes.2010.11.056

20. Davis, C. L., and King, J. E. 1993. Effect of cooling rate on intercritically reheated microstructure and toughness in high strength low alloy steel. Mater. Sci. Technol. 9: 8-15.

21. Davis, C. L., and King, J. E. 1994. Cleavage initiation in the intercritically reheated coarse-grained heat-affected zone: Part I. Fractographic evidence. Metall. Mater. Trans. A 25: 563-573. DOI: 10.1007/BF02651598

22. Reichert, J. M., Garcin, T., Militzer, M., and Poole, W. J. 2014. A new approach using EBSD to quantitatively distinguish complex transformation products along the HAZ in X80 linepipe steel. $9^{\text {th }}$ Int. Pipeline Conf. American Society of Mechanical Engineering, Calgary, $\mathrm{AB}$.

23. Li, X., Ma, X., Subramanian, S. V., Shang, C., and Misra, R. D. K. 2014. Influence of prior austenite grain size on martensiteaustenite constituent and toughness in the heat affected zone of 700MPa high strength linepipe steel. Mater. Sci. Eng. A 616: 141147. DOI: $10.1016 /$ j.msea.2014.07.100

24. Yu, L., Wang, H. H., Hou, T. P., Wang, X. L., Wan, X. L., and Wu, K. M. 2014. Characteristic of martensite-austenite constituents in coarse grained heat affected zone of HSLA steel with varying Al contents. Sci. Technol. Weld. Join. 19: 708-714. DOI: 10.1179/1362171814Y.0000000246

25. Shome, M., Gupta, O. P., and Mohanty, O. N. 2004. Effect of simulated thermal cycles on the microstructure of the heat-affected zone in HSLA-80 and HSLA-100 steel plates. Metall. Mater. Trans. A 35A: 985-996.

26. Spanos, G., Fonda, R. W., Vandermeer, R. A., and Matuszeski, A. 1995. Microstructural changes in HSLA-100 steel thermally cycled to simulate the heat-affected zone during welding. Metall. Mater. Trans. A 26A: 3277-3293.

27. Yang, H. S., and Bhadeshia, H. K. D. H. 2009. Austenite grain size and the martensite-start temperature. Scr. Mater. 60: 493-495. DOI: 10.1016/j.scriptamat.2008.11.043

28. Garcia-Junceda, A., Capdevila, C., Caballero, F. G., Garcia, 
C., and Andre, D. 2008. Dependence of martensite start temperature on fine austenite grain size. Scr. Mater. 58: 134-137. DOI: 10.1016/j.scriptamat.2007.09.017

29. Shome, M. 2007. Effect of heat-input on austenite grain size in the heat-affected zone of HSLA-100 steel. Mater. Sci. Eng. A 445446: 454-460. DOI: 10.1016/j.msea.2006.09.085

30. Zhang, Y. Q., Zhang, H. Q., Li, J. F., and Liu, W. M. 2009. Effect of heat input on microstructure and toughness of coarse grain heat affected zone in Nb microalloyed HSLA steels. J. Iron Steel Res. Int. 16: 73-80. DOI: 10.1016/S1006-706X(10)60014-3

31. Li, X., Fan, Y., Ma, X., Subramanian, S. V., and Shang, C. 2015. Influence of martensite-austenite constituents formed at different intercritical temperatures on toughness. Mater. Des. 67: 457-463. DOI: 10.1016/j.matdes.2014.10.028

32. Prawoto, Y., Jasmawati, N., and Sumeru, K. 2012. Effect of prior austenite grain size on the morphology and mechanical properties of martensite in medium carbon steel. J. Mater. Sci. Technol. 28: 461-466. DOI: 10.1016/S1005-0302(12)60083-8

33. Cao, R., Li, J., Liu, D. S., Ma, J. Y., and Chen, J. H. 2015. Micromechanism of decrease of impact toughness in coarse-grain heat-affected zone of HSLA steel with increasing welding heat input. Metall. Mater. Trans. A 46A: 2999-3014. DOI: 10.1007/ s11661-015-2916-2

34. Xia, Z. H., Wan, X. L., Tao, X. L., and Wu, K. M. 2012. Effect of heat input on toughness of coarse-grained heat-affected zone of an ultra low carbon acicular ferrite steel. Adv. Mater. Res. 538-541: 2003-2008. DOI: 10.4028/www.scientific.net/AMR.538-541.2003

35. Mohammadijoo, M., Kenny, S., Collins, L., Henein, H., and Ivey, D. G. 2017. Influence of cold-wire tandem submerged arc welding parameters on weld geometry and microhardness of microalloyed pipeline steels. Int. J. Adv. Manuf. Technol. 88: 22492263. DOI: $10.1007 / \mathrm{s} 00170-016-8910-z$

36. Mruczek, M. F., and Konkol, P. J. 2006. Cold wire feed submerged arc welding: Technical report. Advanced Technology Institute (ATI), Johnstown, Pa.

37. Ramakrishnan, M., and Muthupandi, V. 2013. Application of submerged arc welding technology with cold wire addition for drum shell long seam butt welds of pressure vessel components. Int. J. Adv. Manuf. Technol. 65: 945-956. DOI: 10.1007/ s00170-012-4230-0

38. Mohammadijoo, M., Kenny, S., Wiskel, J. B., Ivey, D. G., and Henein, H. 2015. Cold-wire tandem submerged arc welding: A novel technique for pipeline manufacturing. 54 ${ }^{\text {th }}$ Annual Conf. Metall. Canadian Institute of Mining, Metallurgy and Petroleum, Toronto, ON: 1-13.

39. Shikanai, N., Mitao, S., and Endo, S. 2007. Recent development in microstructural control technologies through the thermomechanical control process (TMCP) with JFE steel's high-performance. JFE Technical Report No. 18 Plates, JFE Steel, Tokyo.

40. De Meester, B. 1997. The weldability modern structural TMCP steels. ISIJ Int. 37: 537-551.

41. BS, 7448-1: Fracture Mechanics Toughness Tests - Part 1: Method for determination of KIc, Critical CTOD and Critical J Values of Metallic Materials. 1991. British Standard Institute (BSI).

42. Shen, G., Gianetto, J. A., and Tyson, W. R. 2009. Measurement of J-R curves using single-specimen technique on clamped SE(T) specimens. 19 th Int. Offshore Polar Eng. Conf., Osaka, Japan.

43. Lan, W., Deng, X., and Sutton, M. A. 2010. Investigation of crack tunneling in ductile materials. Eng. Fract. Mech. 77: 28002812. DOI: http://dx.doi.org/10.1016/j.engfracmech.2010.06.010

44. Riemelmoser, F., Pippan, R., Weinhandl, H., and Kolednik, O. 1999. The influence of irregularities in the crack shape on the crack extension measurement by means of the direct-currentpotential-drop method BT - The influence of irregularities in the crack shape on the crack extension measurement by means of the direct-Cu. J. Test. Eval. 27: 42-46.

45. Cheng, Y. T., and Cheng, C. M. 2004. Scaling, dimensional analysis, and indentation measurements. Mater. Sci. Eng. R Reports 44: 91-149. DOI: http://dx.doi.org/10.1016/j.mser.2004.05.001

46. ISO, 15653:2010 Metallic Materials-Method of Test for the Determination of Quasistatic Fracture Toughness of Welds. 2010.

47. ASTM, E23-12C: Standard Test Methods for Notched Bar Impact Testing of Metallic Materials. 2012. ASTM International, $\mathrm{Pa}$.

48. LePera, F. S. 1979. Improved etching technique for the determination of percent martensite in high-strength dual-phase steels. Metallography 12: 263-268. DOI: 10.1016/0026-0800(79) 90041-7

49. ASTM, E112-12: Standard Test Methods for Determining Average Grain Size. 2012. ASTM International, Pa. DOI: 10.1520/ E0112-12.1.4

50. ASTM, E562-11: Standard Test Method for Determining Volume Fraction by Systematic Manual Point Count. 2011. ASTM International, Pa. DOI: 10.1520/E0562-11.2

51. Zhu, X. K., and Joyce, J. A. 2012. Review of fracture toughness (G, K, J, CTOD, CTOA) testing and standardization. Eng. Fract. Mech. 85: 1-46. DOI: http://dx.doi.org/10.1016/ j.engfracmech. 2012.02.001

52. Shen, G., and Tyson, W. R. 2009. Crack size evaluation using unloading compliance in single-specimen single-edge notched tension fracture toughness testing. J. Test. Eval. 37(4): JTE102368.

53. ISO, 12135: Metallic Materials - Unified Method of Test for the Determination of Quasistatic Fracture Toughness. 2014.

54. ASTM, E1820-13: Standard Test Method for Measurement of Fracture Toughness. 2013. ASTM International, Conshohocken, Pa.

55. Shen, G., Gianetto, J. A., and Tyson, W. R. 2008. Development of procedure for low-constraint toughness testing using a single-specimen technique. MTL Report No. 2008-18(TR), CanmetMaterials, Ottawa, Canada.

56. Cravero, S., and Ruggieri, C. 2007. Estimation procedure of J-resistance curves for SE(T) fracture specimens using unloading compliance. Eng. Fract. Mech. 74: 2735-2757. DOI: 10.1016/ j.engfracmech.2007.01.012

57. Joyce, J. A., and Link, R. E. 1995. Effect of constraint on upper shelf fracture toughness. Fract. Mech. ASTM STP 1256. ASTM Int., Philadelphia, Pa.: 142-177.

58. Kirk, P. B. S., and Chum, V. 2014. Practical application of low constraint SENT fracture toughness testing for pipeline girth welds. $10^{\text {th }}$ Int. Pipeline Conf: : 1-11.

59. Park, D.-Y., Gravel, J.-P., Hari Manoj Simha, C., Liang, J., and Duan, D.-M. 2016. Low-constraint toughness testing of two singleedge notched tension methods in a single specimen. J. Press. Vessel Technol. 138: 051401. DOI: 10.1115/1.4032998

60. Lucon, E., Weeks, T. S., Gianetto, J. A., Tyson, W. R., and Park, D.-Y. 2015. Fracture toughness characterization of high-pressure pipe girth welds using single-edge notched tension [SE(T)] specimens. Mater. Perform. Charact. 4: 20130098. DOI: 10.1520/ MPC20130098

61. Mohammadijoo, M., Collins, L., Henein, H., and Ivey, D. G. 2017. Evaluation of cold wire addition effect on heat input and productivity of tandem submerged arc welding for low-carbon microalloyed steels. Int. J. Adv. Manuf. Technol. in press: 1-13. DOI: 10.1007/s00170-017-0150-3

62. Somekawa, H., and Mukai, T. 2006. Fracture toughness in an extruded ZK60 magnesium alloy. Mater. Trans. 47: 995-998.

63. Yen, H.-W., Huang, C.-Y., and Yang, J.-R. 2009. Characterization of interphase-precipitated nanometer-sized carbides in a TiMo-bearing steel. Scr. Mater. 61: 616-619. DOI: http://dx.doi.org/ 10.1016/j.scriptamat.2009.05.036

64. Bhadeshia, H. K. D. H. 2013. About calculating the characteristics of the martensite-austenite constituent. Int. Semin. Weld. High Strength Pipeline Steels, CBMM, and The Minerals, Metals and Materials Society (TMS): 99-106.

65. Heinze, C., Pittner, A., Rethmeier, M., and Babu, S. S. 2013. Dependency of martensite start temperature on prior austenite 
grain size and its influence on welding-induced residual stresses. Comput. Mater. Sci. 69: 251-260. DOI: 10.1016/j.commatsci. 2012.11.058

66. Guimaraes, J. R. C., and Rios, P. R. 2010. Martensite start temperature and the austenite grain-size. J. Mater. Sci. 45: 10741077. DOI: 10.1007/s10853-009-4044-0

67. Koistinen, D. P., and Marburger, R. E. 1959. A general equation prescribing the extent of the austenite-martensite transformation in pure iron-carbon alloys and plain carbon steels. Acta Metall. 7: 59-60. DOI: 10.1016/0001-6160(59)90170-1

68. Fisher, J. C., Hollomon, J. H., and Turnbull, D. 1949. Kinetics of the austenite-martensite transformation. Trans. Am. Inst. Min. Metall. Eng. 185: 691-700.

69. Reichert, J. M., Garcin, T., Militzer, M., and Poole, W. J. 2012. Formation of martensite/austenite (M/A) in X80 linepipe steel. $9^{\text {th }}$ Int. Pipeline Conf., Calgary, AB, Canada.

70. Flower, H. M., and Lindley, T. C. 2000. Electron backscattering diffraction study of acicular ferrite, bainite, and martensite steel microstructures. Mater. Sci. Technol. 16: 26-40. DOI: 10.1179/026708300773002636

71. Rodriguez-Ibabe, J. M. 1998. The role of microstructure in toughness behaviour of microalloyed steels. Mater. Sci. Forum. 284286: 51-62. DOI: 10.4028/www.scientific.net/MSF.284-286.51

72. Caballero, F. G., Capdevila, C., and Chao, J. 2010. The microstructure of continuously cooled tough bainitic steels. $2^{\text {nd }}$ Int. Conf. Super-High Strength Steels. Associazione italiana di metallurgia: $10-18$.

\section{Appendix}

The $G\left(a_{i} / W\right)$ parameter in Equation 6 is a function of the

$$
G\left(\frac{a_{i}}{W}\right)=\sum_{i=1}^{12} t_{i}\left(\frac{a_{i}}{W}\right)^{i-1}
$$

The coefficients of the polynomial regression $\left(t_{i}\right)$ based on finite element analyses conducted by Shen et al. (Ref. 55) are shown in Table A1.

Parameters $\eta_{i}{ }^{C M O D}$ and $\gamma_{i}^{L L D}$ in Equation 7 are defined by the finite element analyses performed by Shen et al. (Ref.

52) under a two-dimensional plane strain assumption.

$$
\eta_{C M O D}=\sum_{i=1}^{11} \phi_{i}\left(\frac{a_{i}}{W}\right)^{i}
$$

$$
\gamma_{L L D}=\eta_{L L D}-1-\left(1-\frac{a_{i}}{W}\right)\left(\frac{\eta_{L L D}^{\prime}}{\eta_{L L D}}\right)
$$

$$
\text { where } \eta_{L L D}=\sum_{i=1}^{11} \psi_{k}\left(\frac{a_{i}}{W}\right)^{k}
$$

Coefficients $\phi_{\mathrm{i}}$ and $\psi_{\mathrm{k}}$ are given in Table A2. The first derivative of $\eta_{L L D}$, i.e., $\eta_{L L D}^{\prime}$, is also defined as

$$
\eta_{L L D}^{\prime}=\sum_{i=1}^{11} k \psi_{k}\left(\frac{a_{i}}{W}\right)^{k-1}
$$

The $r_{\mathrm{i}}$ in Equation 8 is the coefficient of a polynomial leastsquares fitting function; values are provided in Table A2.

Table $\mathrm{Al}-$ Coefficient $\mathrm{t}_{\mathrm{i}}$ in Equation $\mathrm{Al}$ for $0.05 \leq \mathrm{a} / \mathrm{W} \leq 0.95$ and $\mathrm{L} / \mathrm{W}=10$

\begin{tabular}{cccccccccccccc}
$\mathrm{i}$ & 1 & 2 & 3 & 4 & 5 & 6 & 7 & 8 & 9 & 10 & 11 & 12 \\
\hline $\mathrm{t}_{\mathrm{i}}$ & 1.20 & -2.13 & 23.89 & -69.05 & 100.46 & -41.40 & -36.14 & 51.21 & -6.61 & -52.32 & 18.57 & 19.47 \\
\hline
\end{tabular}

Table A2 - Coefficients $\phi_{i}$ in Equation A2 and $\psi_{i}$ in Equation A4 Used to Calculate $\eta_{\text {смоD }}^{\prime}$ and $\eta_{\text {смоD }}$, Respectively; Coefficient $r_{i}$ in Equation 8 for $\mathrm{L} / \mathrm{W}=10$

\begin{tabular}{ccccccccccccc}
$\mathrm{i}$ & 1 & 2 & 3 & 4 & 5 & 6 & 7 & 8 & 9 & 10 & 11 \\
\hline$\phi_{\mathrm{i}}$ & 1 & -1.089 & 9.519 & -48.572 & 109.225 & -73.116 & -77.984 & 38.487 & 101.401 & 43.306 & -110.77 \\
$\psi_{\mathrm{i}}$ & -0.88 & 15.19 & -35.44 & 18.64 & 18.40 & -1.27 & -12.76 & -12.20 & -4.45 & 5.40 & 14.19 \\
$\mathrm{r}_{\mathrm{i}}$ & 2.04 & -15.73 & 73.24 & -182.90 & 175.65 & 60.93 & -113.99 & -113.03 & 8.55 & 142.84 & & \\
\hline
\end{tabular}

HANI HENEIN and DOUGLAS G. IVEY (divey@ualberta.ca) are with the Department of Chemical and Materials Engineering, University of Alberta, Edmonton, AB, Canada. MOHSEN MOHAMMADIJOO and LAURIE COLLINS are with the R\&D Division, Evraz Inc. NA, Regina, SK, Canada. ROBERT LAZOR is with TransCanada PipeLines Ltd., Calgary, AB, Canada. 